\title{
Advanced Petroleum-Based Fuels Diesel Emissions Control Project (APBF-DEC)
}

Lubricants Project, Phase 2

Final Report

May 2006
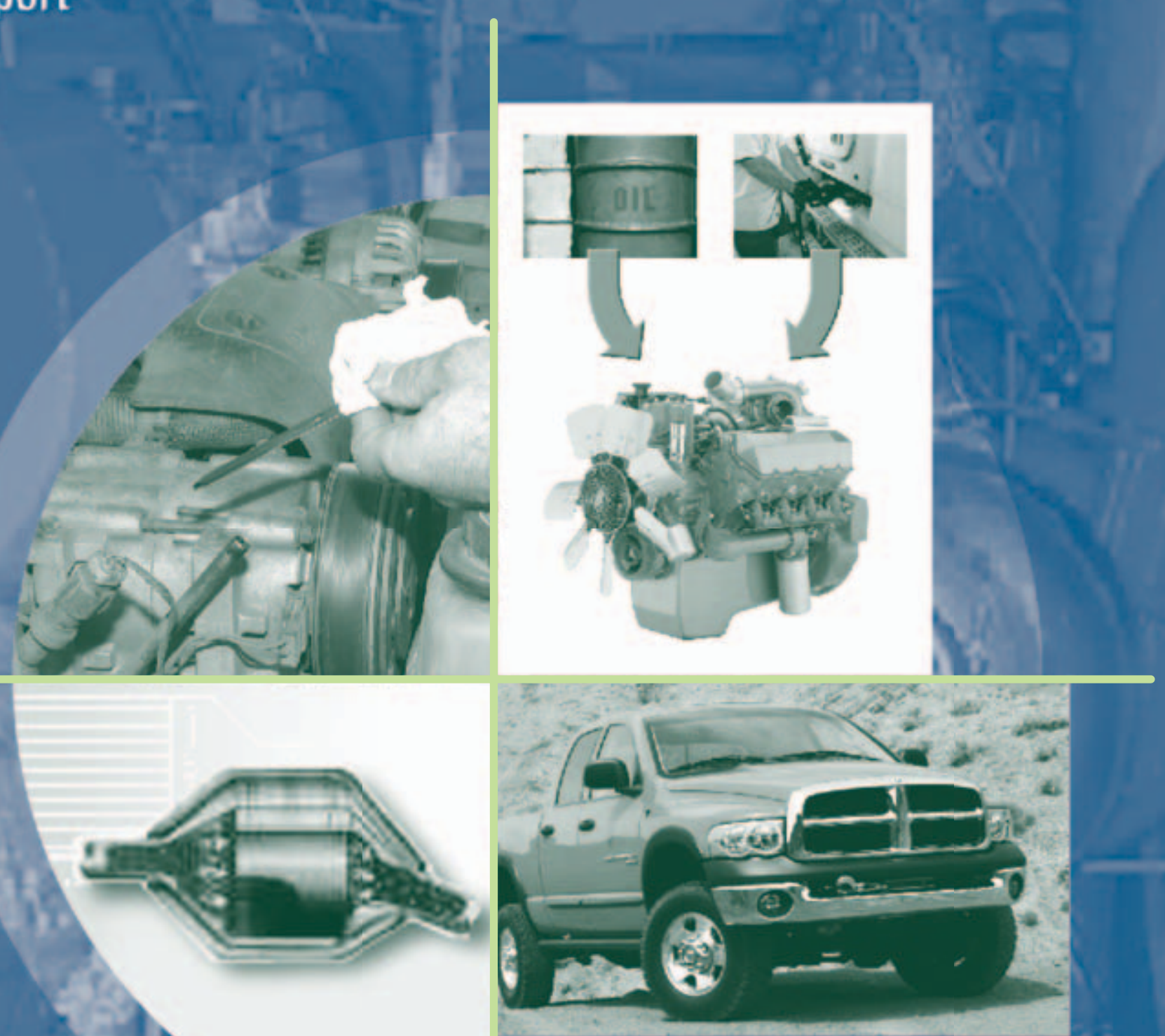

Sponsored by:

The U.S. Department of Energy American Chemistry Council American Petroleum Institute

U.S. Department of Energy

\section{Energy Efficiency} and Renewable Energy

Bringing you a prosperous future where energy is clean, abundant, reliable, and affordable
California Air Resources Board

Engine Manufacturers Association Manufacturers of Emission Controls Association South Coast Air Quality Management District 


\section{NOTICE}

This report was prepared as an account of work sponsored by an agency of the United States government. Neither the United States government nor any agency thereof, nor any of their employees, makes any warranty, express or implied, or assumes any legal liability or responsibility for the accuracy, completeness, or usefulness of any information, apparatus, product, or process disclosed, or represents that its use would not infringe privately owned rights. Reference herein to any specific commercial product, process, or service by trade name, trademark, manufacturer, or otherwise does not necessarily constitute or imply its endorsement, recommendation, or favoring by the United States government or any agency thereof. The views and opinions of authors expressed herein do not necessarily state or reflect those of the United States government or any agency thereof.

Available electronically at http://www.osti.gov/bridge

Available for a processing fee to U.S. Department of Energy and its contractors, in paper, from:

U.S. Department of Energy

Office of Scientific and Technical Information

P.O. Box 62

Oak Ridge, TN 37831-0062

phone: 865.576 .8401

fax: 865.576 .5728

email: mailto:reports@adonis.osti.gov

Available for sale to the public, in paper, from:

U.S. Department of Commerce

National Technical Information Service

5285 Port Royal Road

Springfield, VA 22161

phone: 800.553 .6847

fax: 703.605.6900

email: orders@ntis.fedworld.gov

online ordering: http://www.ntis.gov/ordering.htm

Printed on paper containing at least $50 \%$ wastepaper, including $20 \%$ postconsumer waste 
The test program and subsequent data analysis represent a collaborative effort of a technical working group consisting of representatives from the government and industry organizations listed on the front cover of this report. The work group prepared this report using methods believed to be consistent with accepted practices. All results and observations are based on information available using technologies that were state-of-the-art at the time of this effort. To the extent that additional information becomes available, or factors on which analyses are based change, the findings could subsequently be affected. 


\section{Table of Contents}

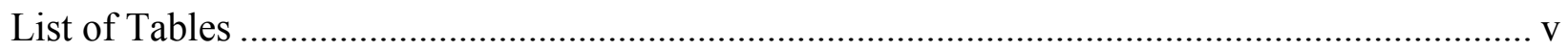

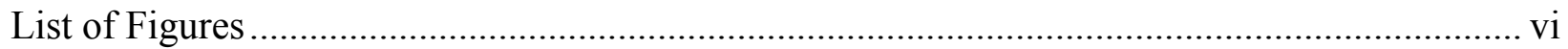

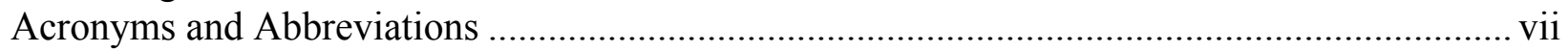

Executive Summary .................................................................................................. vii

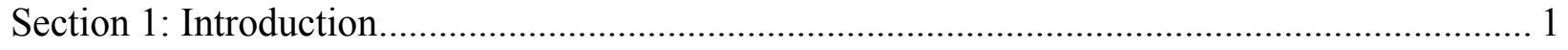

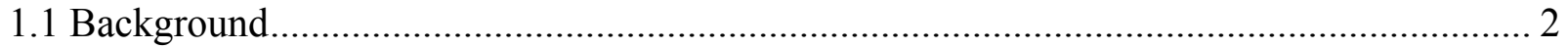

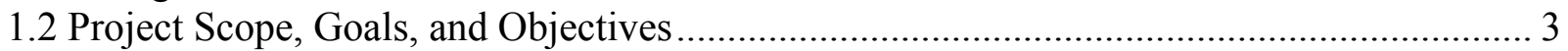

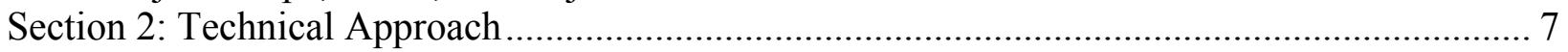

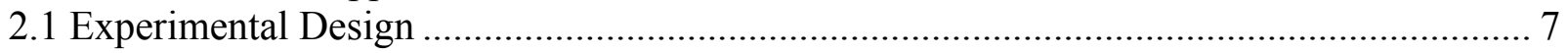

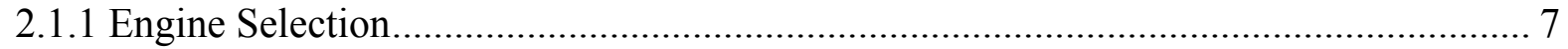

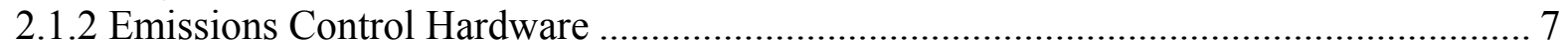

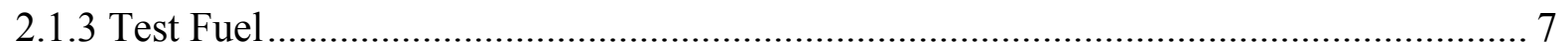

2.1.4 Emissions Measurements and Analysis Methods ....................................................... 8

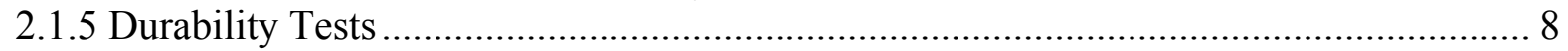

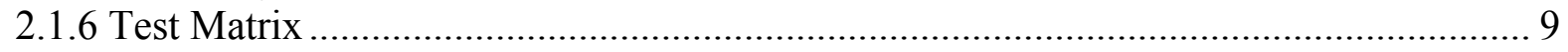

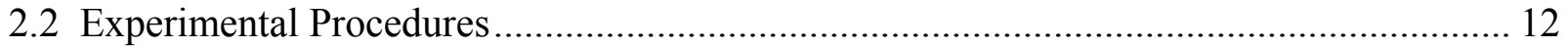

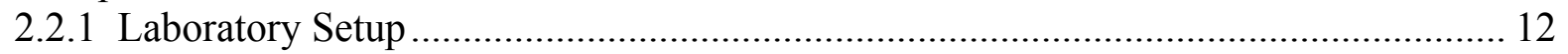

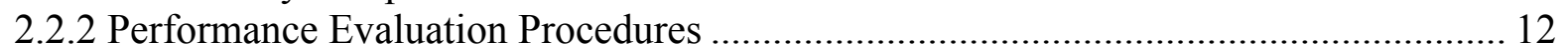

2.2.3 Emissions Sampling and Analysis Procedures........................................................ 14

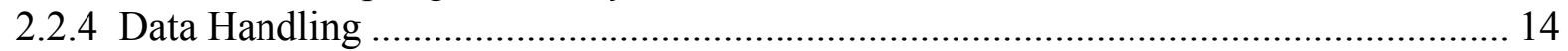

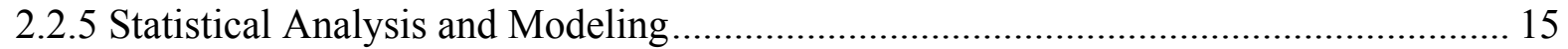

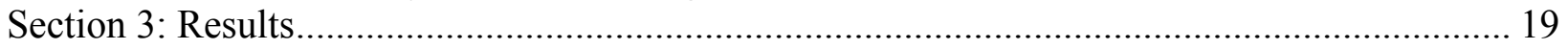

3.1 Exposure of the Catalyst to Engine-Out Emissions........................................................ 19

3.2 Effects of Engine-Out Emissions on Catalyst Deposits ...................................................... 20

3.3 Effects of Engine-Out Emissions on Catalyst Performance .............................................. 25

3.4 Effects of Sulfur and Phosphorus Deposits on Catalyst Performance................................ 29

3.5 Relative Effects of Lubricants and Fuels........................................................................ 32

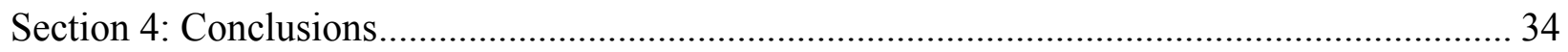

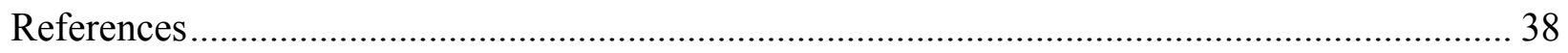

Appendix: Supporting Results from Regression Analyses ........................................................ 39 


\section{List of Tables}

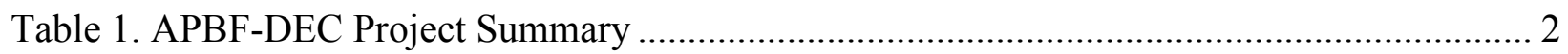

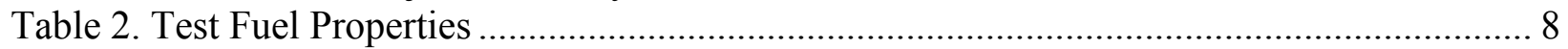

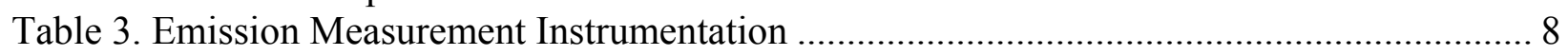

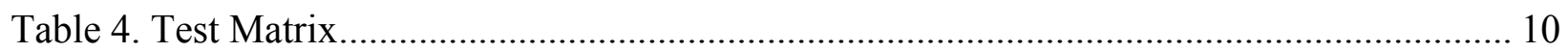

Table 5. Properties of Test Oils ........................................................................................... 11

Table 6. Estimated Engine-Out Emissions and Total Exposures of Catalysts to Sulfur, Phosphorus, and Ash Components (Zinc and Calcium) .......................................................... 20

Table 7. Results of Regression Analyses to Establish Relationships between Exposure Levels

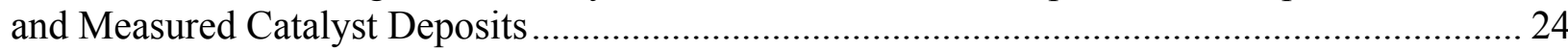

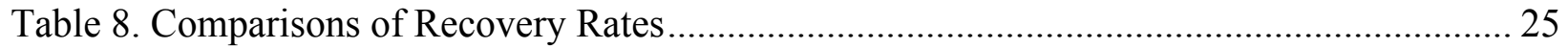

Table 9. Correlation Coefficients from Regressions of $\mathrm{NO}_{\mathrm{x}}$ Performance Measures (NRE and $\triangle \mathrm{NRE}$ ) on Exposures to S+P, Phosphorus , and Calcium

Table 10. Correlation Coefficients from Regressions of $\mathrm{NO}_{\mathrm{x}}$ Performance Measures (NRE and $\triangle \mathrm{NRE}$ ) on Deposit Levels of S+P, Phosphorus, and Calcium

Table 11. Average Exposure and Deposition of Sulfur on the Catalyst during Aging Tests with Lubricant A and 0.6- and 15.0-ppm Sulfur Fuel; Engine and Dosing System Included .............. 32 Table 12. Average Exposure and Deposition of Sulfur on Catalyst during Aging Tests with

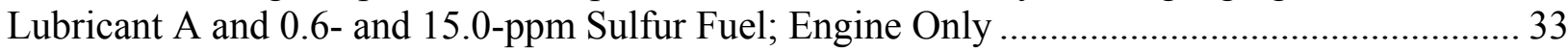

Table A-1. Estimates of Slopes for NRE versus Exposure to Sulfur, S+P, and Calcium ............. 40 Table A-2. Estimates of Slopes for NRE versus Deposit Levels of Sulfur, S+P, and Calcium ... 41 


\section{List of Figures}

Figure ES-1. Effects of lubricants on engine-out emissions .................................................. ix Figure ES-2. Levels of sulfur and phosphorus deposited on the catalyst as a function of the corresponding levels of lubricant-derived exposure and type of calcium detergent used in the lubricant. xiii Figure ES-3. Percentage of total sulfur and phosphorus deposits distributed along the length of the catalyst (front toward engine, rear toward tailpipe)........................................................ xiii Figure ES-4. Change in NRE over 400 hours of testing as a function of the total exposure to lubricant-derived phosphorus emissions......................................................................... xiv Figure ES-5. Comparison of catalyst NRE when testing under three conditions: Oil A (1695 ppm sulfur) with $0.6 \mathrm{ppm}$ sulfur fuel, Oil A with $15 \mathrm{ppm}$ sulfur fuel, and Oil D (4197 ppm sulfur) with 0.6 ppm sulfur fuel. XV Figure 1. The lubricants project investigated the impacts of selected oil and fuel properties on the performance of the NAC ................................................................................................ 4

Figure 2. Lubricants selected for testing in phase 2 ..................................................... 10

Figure 3. Pair-wise plots of measured properties of test oils ............................................. 12

Figure 4. Emissions sampling and measurement schematic .............................................. 14 Figure 5. Comparisons of average sulfur, phosphorus, and calcium deposits as a function of

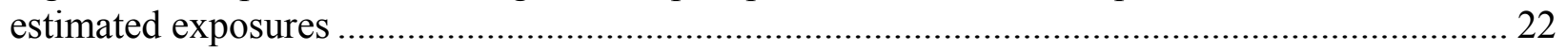
Figure 6. Sulfur, Phosphorus, $\mathrm{S}+\mathrm{P}$, and Calcium deposited at the front, middle, and rear of the

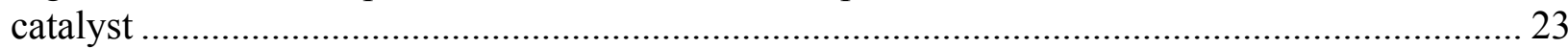

Figure 7. Change in predicted NRE for composite mode vs. phosphorus and calcium exposure to catalysts through 200 to 400 hours of aging ................................................................... 28 Figure 8. Change in predicted NRE for composite mode vs. phosphorus and calcium deposited on the aged catalysts through 200 to 400 hours of aging...

Figure 9. Comparison of catalyst NRE when testing under three conditions: Oil A (1695 ppm sulfur) with 0.6-ppm sulfur fuel, Oil A with 15-ppm sulfur fuel, and Oil D (4197 ppm sulfur) with 0.6-ppm sulfur fuel

Figure 10. Levels of sulfur and phosphorus deposited on the catalyst as a function of the corresponding levels of lubricant-derived exposure and type of calcium detergent used in the lubricant

Figure 11. Percentage of total sulfur and phosphorus deposits distributed along the length of the catalyst (front toward engine, rear toward tailpipe). 35

Figure 12. Change in NRE over 400 hours of testing as a function of the total exposure to lubricant-derived phosphorus emissions 36 Figure 13. Comparison of catalyst NRE when testing under three conditions: Oil A (1695 ppm sulfur) with $0.6 \mathrm{ppm}$ sulfur fuel, Oil A with $15 \mathrm{ppm}$ sulfur fuel, and Oil D (4197 ppm sulfur) with 0.6 ppm sulfur fuel..... 37

Figure A-1. NRE versus aging time for composite mode and modes 1 to 6 42 


\section{Acronyms and Abbreviations}

\begin{tabular}{|c|c|}
\hline $\mathrm{ACC}$ & American Chemistry Council \\
\hline APBF-DEC & Advanced Petroleum-Based Fuels_-Diesel Emission Control \\
\hline API & American Petroleum Institute \\
\hline ASTM & American Society for Testing and Materials \\
\hline bhp & brake horsepower \\
\hline $\mathrm{Ca}$ & calcium \\
\hline CARB & California Air Resources Board \\
\hline $\mathrm{CO}$ & carbon monoxide \\
\hline $\mathrm{CO}_{2}$ & carbon dioxide \\
\hline DECSE & Diesel Emissions Control-Sulfur Effects \\
\hline $\mathrm{DOC}$ & diesel oxidation catalyst \\
\hline DOE & U.S. Department of Energy \\
\hline DPF & diesel particle filter \\
\hline EMA & Engine Manufacturers Association \\
\hline EPA & U.S. Environmental Protection Agency \\
\hline $\mathrm{g} / \mathrm{bhp} \mathrm{hr}$ & grams per brake horsepower hour \\
\hline $\mathrm{HC}$ & hydrocarbons \\
\hline hp & horsepower \\
\hline $\mathrm{kW}$ & kilowatt \\
\hline $\mathrm{L}$ & liter \\
\hline lb/bhp-hr & pound per brake horsepower hour \\
\hline MECA & Manufacturers of Emission Controls Association \\
\hline $\mathrm{mg} / \mathrm{bhp}-\mathrm{hr}$ & milligram per brake horsepower hour \\
\hline $\mathrm{mg} \mathrm{KOH} / \mathrm{g}$ & milligrams of potassium hydroxide per gram \\
\hline mil & millimeter \\
\hline NAC & nitrogen oxide adsorber catalyst \\
\hline $\mathrm{NO}_{\mathrm{x}}$ & nitrogen oxides \\
\hline NPRA & National Petrochemical and Refiners Association \\
\hline NRE & nitrogen oxide reduction efficiency \\
\hline $\mathrm{O}_{2}$ & oxygen \\
\hline $\mathrm{P}$ & phosphorus \\
\hline $\mathrm{PC}$ & proposed category \\
\hline PM & particulate matter \\
\hline ppm & parts per million \\
\hline $\mathrm{rpm}$ & revolutions per minute \\
\hline $\mathrm{S}$ & sulfur \\
\hline SCAQMD & South Coast Air Quality Management District \\
\hline $\mathrm{SO}_{2}$ & sulfur dioxide \\
\hline $\mathrm{S}+\mathrm{P}$ & sulfur plus phosphorus \\
\hline SUV & sport-utility vehicle \\
\hline $\mathrm{TBN}$ & total base number \\
\hline TDI & turbo direct injection \\
\hline $\mathrm{XRF}$ & $\mathrm{X}$-ray fluorescence \\
\hline ZDDP & zinc dialkyl-dithiophosphate \\
\hline $\mathrm{Zn}$ & zinc \\
\hline
\end{tabular}




\section{Executive Summary}

The Advanced Petroleum-Based Fuels-Diesel Emission Control (APBF-DEC) program was a government/industry collaboration seeking the optimal combinations of low-sulfur diesel fuels, lubricants, diesel engines, and emission control systems to meet projected emission standards for the 2004 to 2010 time period. APBF-DEC consisted of five projects that used a systems approach to enhance the collective knowledge base on engines, diesel fuels, lubricants, and emission control technologies. The five test projects evaluated the following:

- Selective catalytic reduction/diesel particle filter (DPF) technologies

- Nitrogen oxide adsorber catalyst (NAC)/DPF technologies for passenger cars, light-duty trucks/sport-utility vehicles, and heavy-duty applications (three projects on different engine/vehicle platforms)

- Lubricant formulations that may affect the performance and durability of advanced diesel emission control systems.

The APBF-DEC program was sponsored and conducted by a broad collaboration of government and industry organizations including: the U.S. Department of Energy (DOE), the American Chemistry Council (ACC), the American Petroleum Institute (API), the Engine Manufacturers Association (EMA), the Manufacturers of Emission Controls Association (MECA), the California Air Resources Board (CARB), and the South Coast Air Quality Management District (SCAQMD).

This report summarizes the results of the second phase of the lubricants project, which investigated the impact of engine oil formulation on emissions and the performance of a NAC.

\section{Introduction}

New emission regulations for light- and heavy-duty engines that will be phased in later this decade will necessitate the use of advanced emission control technologies including catalysts and filters. Some of the new technologies in development have been demonstrated to have a sensitivity to fuel-borne sulfur, and regulations limiting the permissible levels of sulfur in diesel fuel will take effect in 2006 in anticipation of their use. However, the sensitivity of the devices is so extreme, and the durability requirements of heavy-duty commercial vehicles are so demanding (up to 435,000 miles), that a reduced fuel sulfur level may not be enough to guarantee the long-term performance of new emission control systems, if other sources of catalyst poisons are found to exist.

Diesel lubricant is known to be consumed during the normal operation of the engine in small but not insignificant quantities. While the quantities may be small, the sulfur content in engine oil is typically higher than that of fuel by an order of magnitude or more, elevating the level of concern accordingly. Other constituents of the lubricating oil, such as wear control additives, have been found to be an issue for three-way catalysts used with gasoline engines and may cause similar problems in diesel emission control systems. 
In anticipation of such challenges, engine makers and the oil and additive industry are actively developing a new specification for lubricating oil to be used in catalyst-equipped diesel engines. This specification, Proposed Category 10 (PC-10), is scheduled for adoption by 2006 and may trigger the most drastic changes in oil formulation in many years. However, because of the limited experience with these new emission control technologies, little data currently exist to quantify the benefit of these new standards. Limits on sulfur and phosphorus or the additives that contain them could have a significant impact on the performance of the lubricant, compromising engine durability and oil drain intervals, both of which have a significant impact on the vehicle owner's profitability.

It is therefore critical that the effects that lubricants have on emissions be well quantified and evaluated so that appropriate lubricants can be developed to protect the emission control systems while continuing to provide superior engine protection.

\section{Project Overview}

The goal of the APBF-DEC Lubricants Project was to generate practical information for lubricant marketers, additive companies, engine manufacturers, and emission control system suppliers related to the impacts of lubricant properties on the performance of diesel emission control systems. Specifically, the project focused on the impacts of lubricant-derived emissions on a NAC system. The project was divided into two phases (Figure ES-1). Phase 1 investigated how various lubricant formulations impact engine-out emissions, while Phase 2 studied how selected oil properties - primarily the level of zinc dialkyl-dithiophosphate (ZDDP) and the level and type of calcium detergent - affect the condition and performance of a NAC.

Phase 1
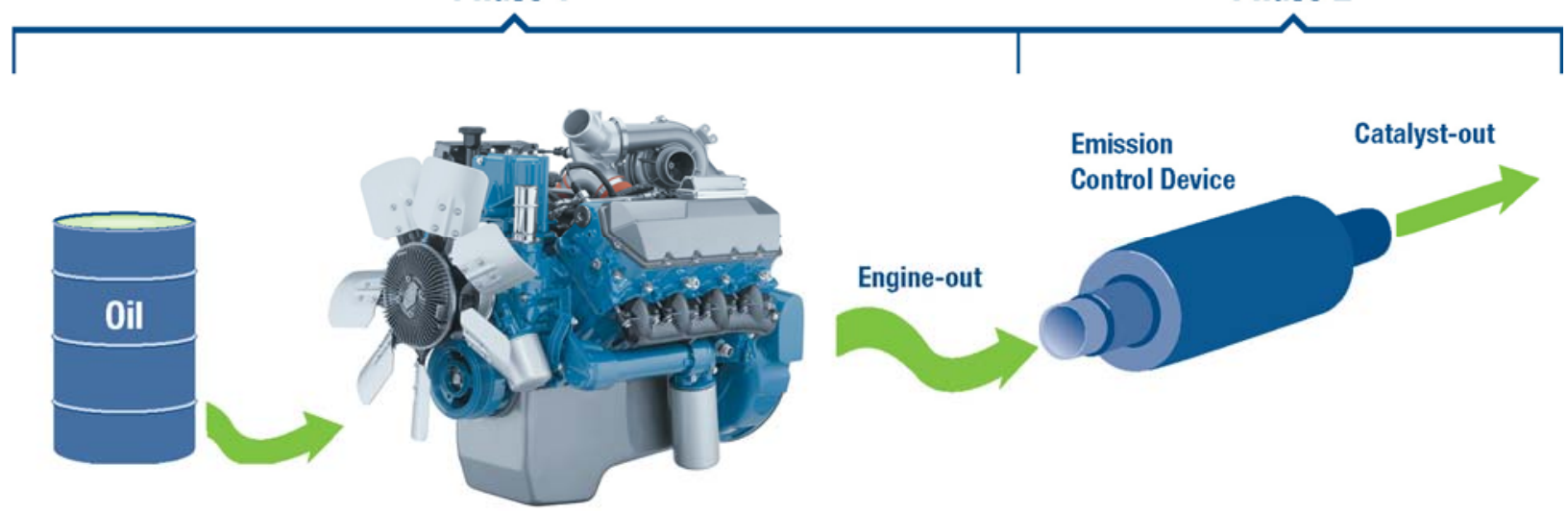

Phase 2

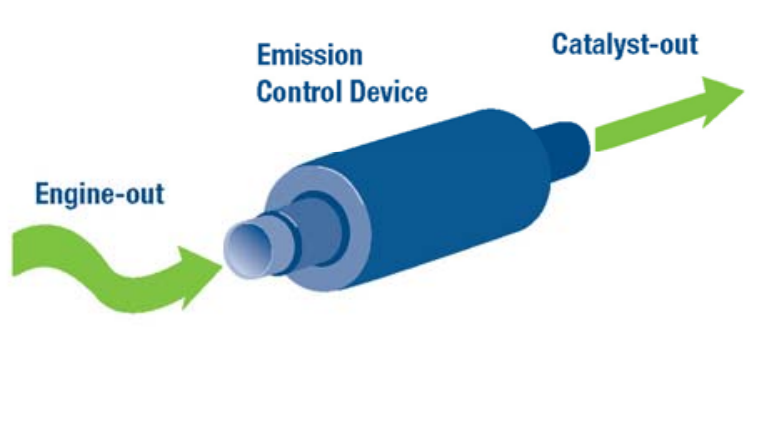

Figure ES-1. Effects of lubricants on engine-out emissions 


\section{Objective}

The objective of Phase 2 was to evaluate the impacts of oil-derived emissions on the condition and performance of a NAC. The work builds upon results from the first phase of the study, which focused only on engine-out emissions (no catalyst) [4]. In particular, the project is designed to study how various lubricant additives, including ZDDP and detergents, influence NAC performance.

\section{Research Questions}

To achieve the Phase 2 objectives, a series of study questions were developed to guide the experimental design and data analysis. They are organized into the following five categories:

\section{Exposure of the Catalyst to Engine-Out Emissions}

Q1.1 What are the engine-out emissions of sulfur, phosphorus, and ash components (zinc and calcium) using each of the oils tested?

Q1.2 What was the total exposure of the test catalysts to these elements during 400 hours of aging?

\section{Effects of Engine-Out Emissions on Catalyst Deposits}

Q2.1 What is the relationship between the catalyst exposures to sulfur, phosphorus, and ash components and the amount of these elements deposited on the catalysts?

Q2.2 How do the levels of deposits vary across the length of the catalysts?

Q2.3 Does the level of calcium detergent in the lubricant affect the amount of sulfur or phosphorus that is deposited on the catalyst?

Q2.4 Does the type of calcium detergent affect the amount of sulfur and phosphorus deposited on the catalyst?

\section{Effects of Engine-Out Emissions on Catalyst Performance}

Q3.1 How does the catalyst performance vary as a function of total exposures to sulfur, phosphorus, and calcium?

Q3.2 Do other oil properties provide a better fit to the performance measures?

\section{Effects of Sulfur and Phosphorus Deposits on Catalyst Performance}

Q4.1 How does the catalyst performance vary as a function of the level of sulfur, phosphorus, and calcium deposits on the catalyst? 


\section{Relative Effects of Lubricants and Fuels}

Q5.1 How do lubricant contributions to engine-out sulfur emissions and the sulfur deposits on the catalysts compare to those attributable to 15 -ppm sulfur fuel?

Q5.2 How does the degradation in nitrogen oxide reduction efficiency (NRE) due to lubricant properties compare to the degradation that occurs with 15-ppm sulfur fuel?

\section{Methods}

This study consisted of a series of eight 400-hour aging tests with a matrix of lubricants containing the same low-sulfur Group II base oil, but varying levels of ZDDP and calcium detergents. The engine selected for the project was a 2003 Cummins ISB (5.9L, $300 \mathrm{hp}$ ) engine equipped with cooled exhaust gas recirculation. For each test, a new NAC was installed. The catalysts, provided by a MECA member company, represented the state-of-the-art at the time at which they were supplied. The catalyst volume of 7 liters $(9.5$ in. diameter $\times 6$ in. length) was slightly but deliberately undersized for this application. Upon installation of the engine and emission control system in the test cell, a regeneration system including a stainless steel fuel injector was installed in the exhaust to deliver reductant fuel at a rate dictated by the operating mode and commanded by the test cell computer.

An aging cycle consisting of six steady-state modes was developed to cycle the engine and catalyst through a variety of exhaust temperatures and space velocities. Throughout the aging period, the engine was cycled through each of the test modes at 30-minute intervals. Regeneration frequency varied by mode and ranged from every 25 to every 60 seconds.

Evaluations of catalyst performance were conducted after 10, 100, 200, 300, and 400 hours of aging. The evaluation protocol borrowed from the aging cycles, with nitrogen oxides $\left(\mathrm{NO}_{\mathrm{x}}\right)$, carbon monoxide, carbon dioxide, hydrocarbons, and sulfur dioxide measured at each of the six steady-state test modes. Results from each test mode were used to calculate a composite emissions rate at each evaluation point. Tailpipe (post-catalyst) emissions were compared with engine-out (pre-catalyst) emissions to determine the NRE of the catalyst.

All tests were conducted with the Diesel Emissions Control - Sulfur Effects (DECSE), ultra-low sulfur fuel (0.6-ppm sulfur) with the exception of the eighth test, which used the DECSE base fuel doped to contain15-ppm sulfur. After each test, the engine oil was changed to the next test oil using a triple-flush procedure to avoid any carryover effects from previous tests. The engine oil was also changed after 200 hours of operation (the midpoint of the aging test) because some of the test oils contained low levels of anti-wear and detergent additives. A gravimetric procedure was used to track oil consumption rate during all of the aging tests. Oil samples were taken from the engine at 50-hour intervals and then analyzed for metals, soot content, total base number (TBN), and viscosity.

After testing was completed, deposit measurements were conducted on the aged catalysts using UniQuant x-ray fluorescence analysis. Samples from the front, middle, and rear of each catalyst were analyzed for sulfur, phosphorus, and calcium. 


\section{Phase 2 Findings and Conclusions}

The following is a summary of the significant conclusions from the study. Further details are provided in Section 3 of the report.

\section{Lube-Derived Emissions versus Sulfur and Phosphorus Deposits on the Catalyst}

- The amount of phosphorus deposited on the catalyst is correlated with the concentration of phosphorus in the lubricant, regardless of the type of calcium detergent used.

- When oils with a calcium sulfonate detergent are used, the levels of both phosphorus and sulfur deposited on the catalyst are highly correlated with their concentration in the oil. However, the percentages of exposed phosphorus and sulfur that are deposited on the catalyst are significantly reduced (by 54\%) when the lubricant contains higher levels $(>3,100 \mathrm{ppm}$ versus $<2,200 \mathrm{ppm})$ of calcium sulfonate detergent (Figure ES-2).

- Approximately $50 \%$ of the accumulated sulfur is deposited in the front third of the catalyst. The middle and rear of the catalyst receive approximately $30 \%$ and $20 \%$ of the sulfur, respectively. The corresponding percentages of phosphorus deposits are approximately $70 \%, 20 \%$, and $10 \%$, respectively (Figure ES-3).

Although these findings are statistically significant, additional research is needed to reach definitive conclusions concerning the role of calcium detergent in reducing the amounts of lubricant-derived sulfur and phosphorus deposited on catalysts. Also, system design, especially the order of emission control components in the exhaust system, will to a large extent dictate the system's sensitivity to lubricant derived species. In this study, the NAC was the first and only device in the exhaust. Other systems may employ DPFs and/or diesel oxidation catalysts in front of the $\mathrm{NO}_{\mathrm{x}}$ adsorber. With those designs, one might expect a majority of the lube components to be trapped by the device prior to reaching the $\mathrm{NO}_{\mathrm{x}}$ adsorber. Nonetheless, the effects observed in this study should be considered when next-generation engines and oils used in those engines are developed. 


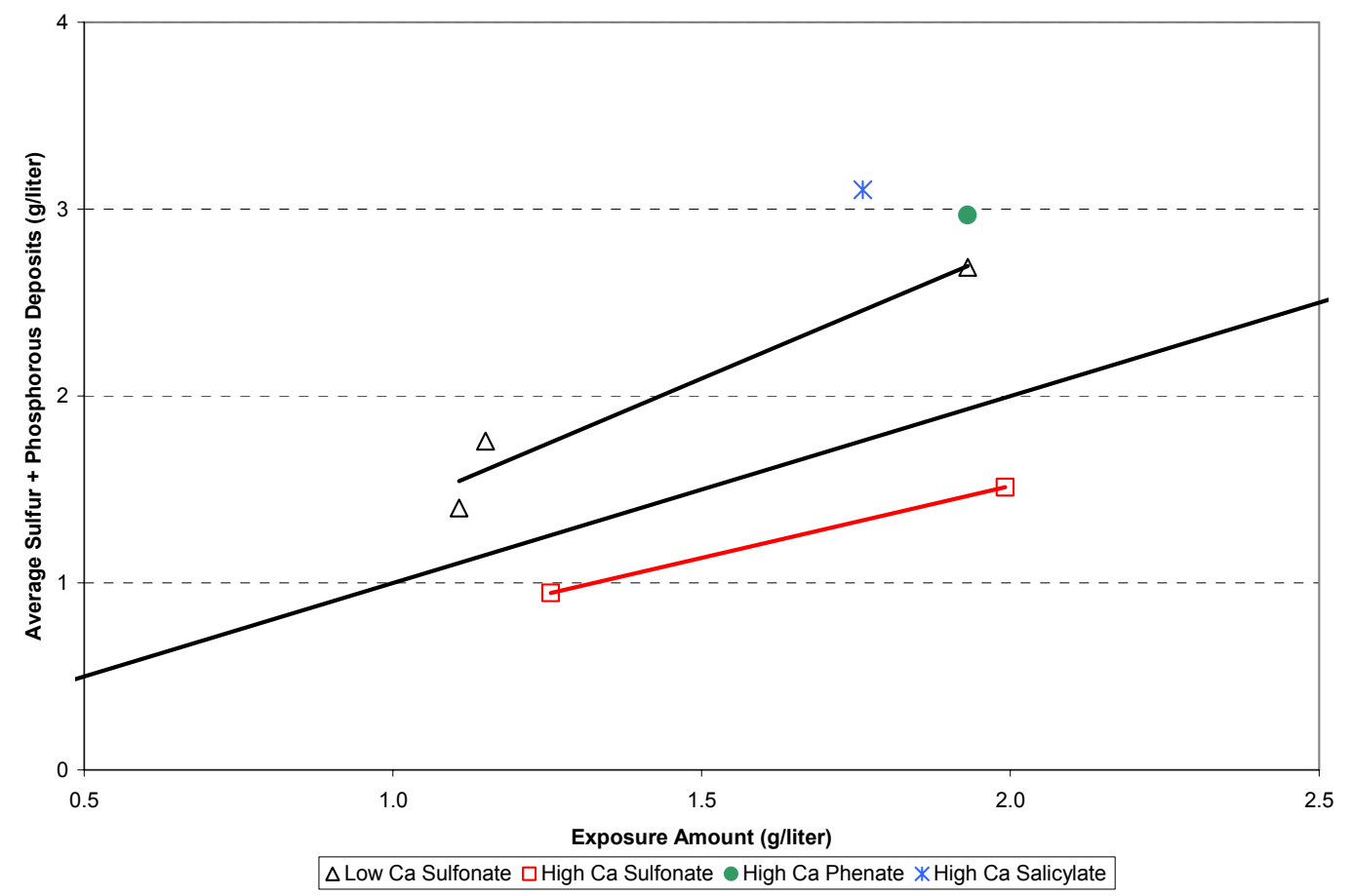

Figure ES-2. Levels of sulfur and phosphorus deposited on the catalyst as a function of the corresponding levels of lubricant-derived exposure and type of calcium detergent used in the lubricant
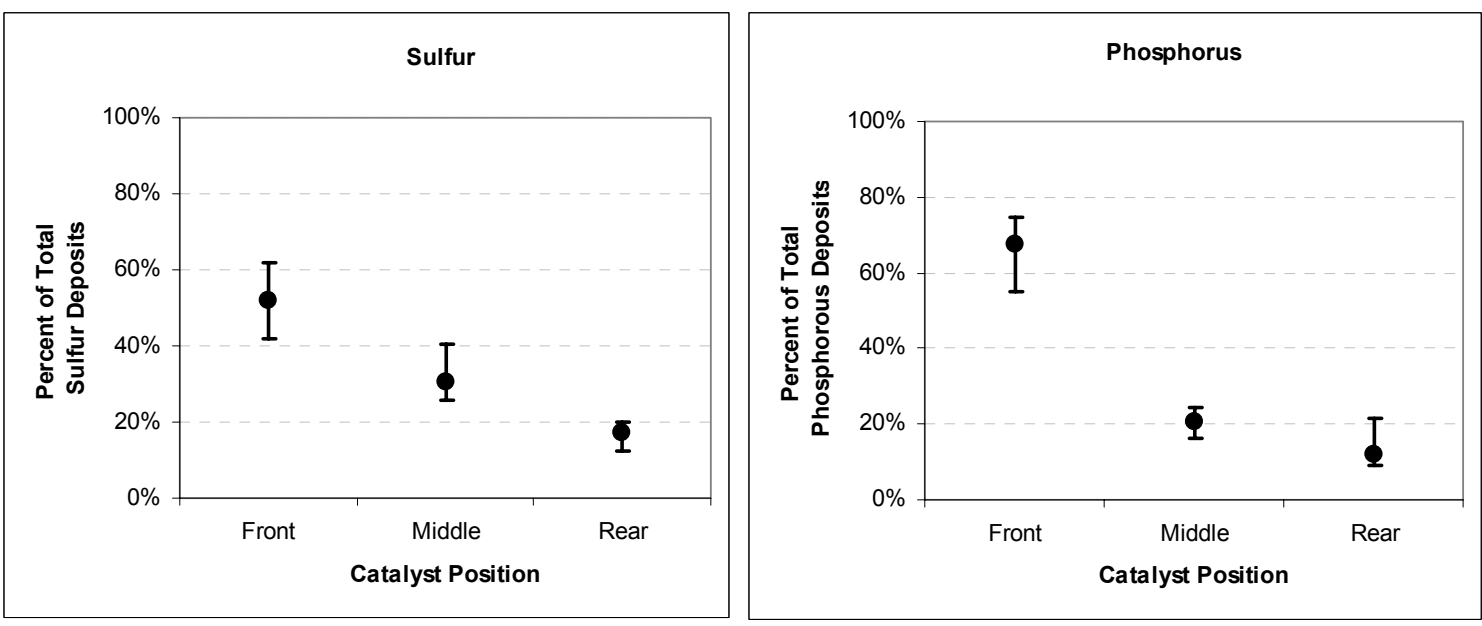

Figure ES-3. Percentage of total sulfur and phosphorus deposits distributed along the length of the catalyst (front toward engine, rear toward tailpipe) 


\section{Catalyst Performance versus Exposure to Lubricant-Derived Sulfur and Phosphorus}

The $\mathrm{NO}_{\mathrm{x}}$ reduction efficiency (NRE) of the catalyst was significantly affected $\left(\mathrm{R}^{2}=78 \%\right)$ by the level of phosphorus in the lubricant. As shown in Figure ES-4, NRE decreased by $70 \%$ after 400 hours of testing with high levels of lubricant-derived phosphorus exposure $(\sim 0.35 \mathrm{~g} / 1)$. The decrease was $40 \%$ with phosphorus exposures of approximately $0.1 \mathrm{~g} / \mathrm{l}$. The initial NRE of the catalyst was between $75 \%$ and $90 \%$.

Because the levels of phosphorus and sulfur in the tested lubricants were correlated, it is not possible to determine which element had the greater effect on catalyst performance. Both elements were deposited on the catalyst, suggesting that lubricants containing higher concentrations of ZDDP adversely impact NAC performance. Further investigation would be required to characterize the nature of the deposits and the mechanism of the deactivation.

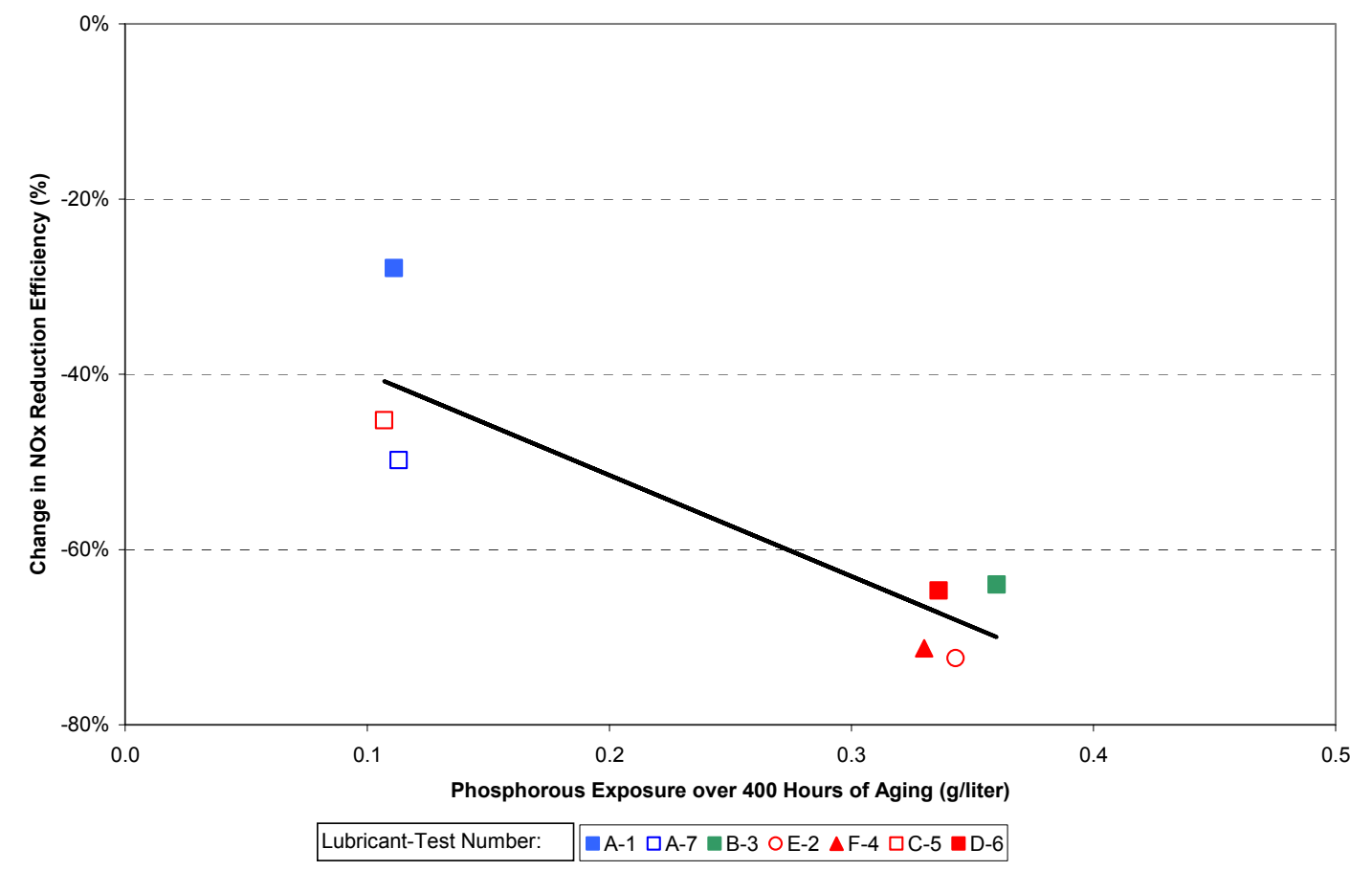

Figure ES-4. Change in NRE over 400 hours of testing as a function of the total exposure to lubricant-derived phosphorus emissions 


\section{Relative Contributions of Lubricant and Fuel Properties on Catalyst Performance}

NRE of the catalyst was reduced by $40 \%$ over 400 hours when the low-sulfur oil (Oil A with 1695 ppm sulfur) was tested with 0.6 ppm sulfur fuel; however, when the same oil was tested with 15 ppm sulfur fuel, there was a 40\% drop in NRE within the first 100 hours. Tests with high-sulfur oil (Oil D with $4197 \mathrm{ppm}$ sulfur) and the $0.6 \mathrm{ppm}$ sulfur fuel yielded intermediate results (Figure ES-5).

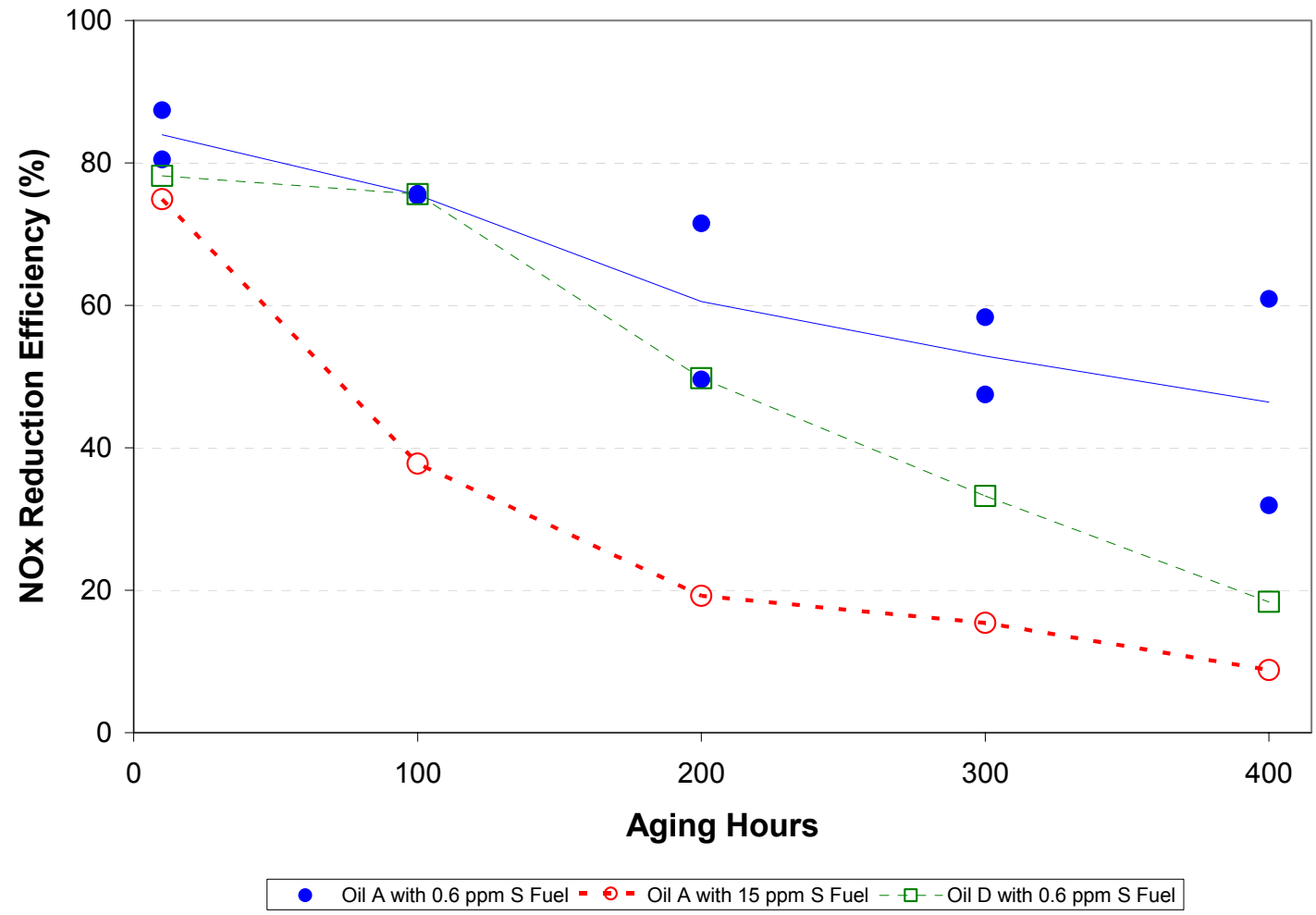

Figure ES-5. Comparison of catalyst $\mathrm{NO}_{\mathrm{x}}$ reduction efficiency when testing under three conditions: Oil A (1695 ppm sulfur) with 0.6 ppm sulfur fuel, Oil A with 15 ppm sulfur fuel, and Oil D (4197 ppm sulfur) with 0.6 ppm sulfur fuel

\section{Future Work}

The results of this work have identified a number of areas worthy of additional study. Some of these recommendations are summarized here.

- The sensitivity of a given emission control system will be largely dependent on the specific design of the system. Further research should focus on fully integrated $\mathrm{NO}_{\mathrm{x}}$ and particulate matter control systems.

- This work identified a potential benefit from certain detergent additives in the mitigation of catalyst deposits and associated performance loss. A more fundamental and robust investigation of this synergy is recommended. 
- The fluids tested in this study were limited to low-sulfur API Group II base oils. As long as there is a market for lower-quality base stocks, especially those containing higher levels of sulfur, further work is recommended to determine their effect on emission control system performance.

Oil formulators face a number of often conflicting demands in the development of high quality lubricants. As emission control system compatibility continues to place more constraints on these formulations, the APBF-DEC Lubricant Project team recommends that continued research be focused on development of novel, high-performance technologies that simultaneously offer superior engine protection and catalyst compatibility. 


\section{Section 1: Introduction}

The Advanced Petroleum-Based Fuels-Diesel Emission Control (APBF-DEC) was a government/industry project to identify and evaluate:

- The optimal combinations of low-sulfur diesel fuels, lubricants, diesel engines, and emission control systems to meet projected emission standards for the 2001 to 2010 time period

- Properties of fuels and vehicle systems that could lead to even lower emissions beyond 2010.

The project was funded and directed by federal and state government agencies, trade associations, and private industry. The primary sponsors were the U.S. Department of Energy (DOE), the American Chemistry Council (ACC), the American Petroleum Institute (API), the Engine Manufacturers Association (EMA), the Manufacturers of Emission Controls Association (MECA), the California Air Resources Board (CARB), and the South Coast Air Quality Management District (SCAQMD).

The U.S. Environmental Protection Agency (EPA) provided technical assistance. Additional technical support was provided by the National Petrochemical and Refiners Association. Representatives from these and other agencies, associations, national laboratories, and private sector companies served on a 20-member APBF-DEC Steering Committee and its working groups.

A systems approach was used to simultaneously investigate how fuels, lubricants, engines, and emission control systems can enable clean and efficient transportation systems. APBF-DEC consisted of five individual projects that evaluated how sulfur and other compounds impact the performance and durability of advanced diesel emission control systems. The projects are summarized in Table 1. 
Table 1. APBF-DEC Project Summary

\begin{tabular}{|c|c|c|c|}
\hline Technology & Platform & Test Vehicle/Engine & Subcontractor \\
\hline \multirow{3}{*}{$\begin{array}{l}\mathrm{NO}_{x} \text { Adsorber Catalysts } \\
\text { and Diesel Particle } \\
\text { Filters }\end{array}$} & Light-Duty & $\begin{array}{l}\text { 1.9L TDI } \\
\text { Audi A4 }\end{array}$ & FEV \\
\hline & SUV/Light Truck & $\begin{array}{l}\text { Chevrolet Silverado } \\
\text { Isuzu/GM Duramax }\end{array}$ & Southwest Research Institute \\
\hline & Heavy-Duty & $\begin{array}{l}\text { Cummins ISX } \\
\text { (engine only) }\end{array}$ & Ricardo, Inc. \\
\hline $\begin{array}{l}\text { Urea Selective Catalytic } \\
\text { Reduction and Diesel } \\
\text { Particle Filters }\end{array}$ & Heavy-Duty & Caterpillar C12 & Southwest Research Institute \\
\hline Lubricants & Medium-Duty & $\begin{array}{l}\text { International T444E } \\
\text { (Phase 1) } \\
\text { Cummins ISB (Phase 2) }\end{array}$ & $\begin{array}{l}\text { Automotive Testing } \\
\text { Laboratories (Phase 1) } \\
\text { Analytical Engineering, Inc. } \\
\text { (Phase 2) }\end{array}$ \\
\hline
\end{tabular}

This report summarizes the results from Phase 2 of the APBF-DEC Lubricants project.

\subsection{Background}

The previously completed Diesel Emission Control - Sulfur Effects (DECSE) project quantified the impact of diesel fuel sulfur on the performance and short-term durability of diesel emission control devices [diesel oxidation catalysts (DOCs), lean-nitrogen oxide $\left(\mathrm{NO}_{\mathrm{x}}\right)$ catalysts, $\mathrm{NO}_{\mathrm{x}}$ adsorber catalysts (NACs), and diesel particle filters (DPFs)]. Because some of these new technologies have demonstrated a sensitivity to fuel-borne sulfur, considerable research was conducted, and regulations limiting the permissible levels of sulfur in diesel fuel were promulgated. Beginning in October 2006, on-highway diesel fuel will be subject to a maximum sulfur content of $15 \mathrm{ppm}$. However, the sensitivity of the emission control devices is so extreme, and the durability requirements of heavy-duty commercial vehicles are so long, that a reduced fuel sulfur level may not be enough to guarantee the long-term performance of new emission control systems, if other sources of catalyst poisons are found to exist.

Diesel lubricant is known to be consumed during the normal operation of the engine in small but not insignificant quantities. While the quantities may be small, the sulfur content of the lubricant is typically higher than that of fuel by an order of magnitude or more, elevating the level of concern accordingly. Other constituents of the lubricating oil, such as anti-wear additives, have been found to be a potential problem for gasoline systems [1,2] and are expected to cause similar concerns for diesel emission control systems.

For these reasons, a separate project was planned within APBF-DEC to look specifically at lubricant effects on catalyst durability and emissions. Meanwhile, the industry is actively developing a new category of diesel lubricants for use in catalyst-equipped engines [Proposed Category 10 (PC-10)]. The results of this study will provide critical information to the developers of this new performance standard and those that follow.

The first phase of this work included a thorough characterization of the impact of lubricant base stock and additive chemistry on the emissions from a medium-duty engine [4]. In general, that study concluded that: 
- Oil formulation has statistically significant effects on nearly every emissions component.

- Additives and base oils affect emissions.

- The effects of additives are not the same for each base oil.

- The emissions of lubricant-derived metals are highly correlated with emissions predicted from the composition of the oil and fuel; however, recovery rates vary significantly (ranging from $17 \%$ for $\mathrm{Mg}$ to $125 \%$ for sulfur) and certain oils significantly deviate.

Phase 1 also included a study to develop a technique for realistically accelerating oil consumption. Of the two methods studied (fuel/lube blending, and spraying oil into the exhaust manifold), neither was deemed suitable for use in the Phase 2 aging tests.

\subsection{Project Scope, Goals, and Objectives}

The primary goal of the APBF-DEC Lubricants Project is to generate practical information for lubricant marketers, additive companies, engine manufacturers, and emission control system suppliers related to the impacts of lubricant properties on the performance of diesel emission control systems. Specifically, the project focused on the impacts of lubricant-derived emissions on a NAC system. Figure 1 describes the two phases involved in this study. Phase 1 investigated how various lubricant formulations impact engine-out emissions (A versus B), while Phase 2 studied how selected oil properties [primarily the level of zinc dialkyl-dithiophosphate (ZDDP) and the level and type of calcium detergent] affect the condition (B versus $\mathrm{C}$ ) and performance $(\mathrm{C}$ versus $\mathrm{D})$ of a NAC. All of the tests were performed with ultra-low sulfur fuel ( 0.6 to $15 \mathrm{ppm}$ sulfur). 


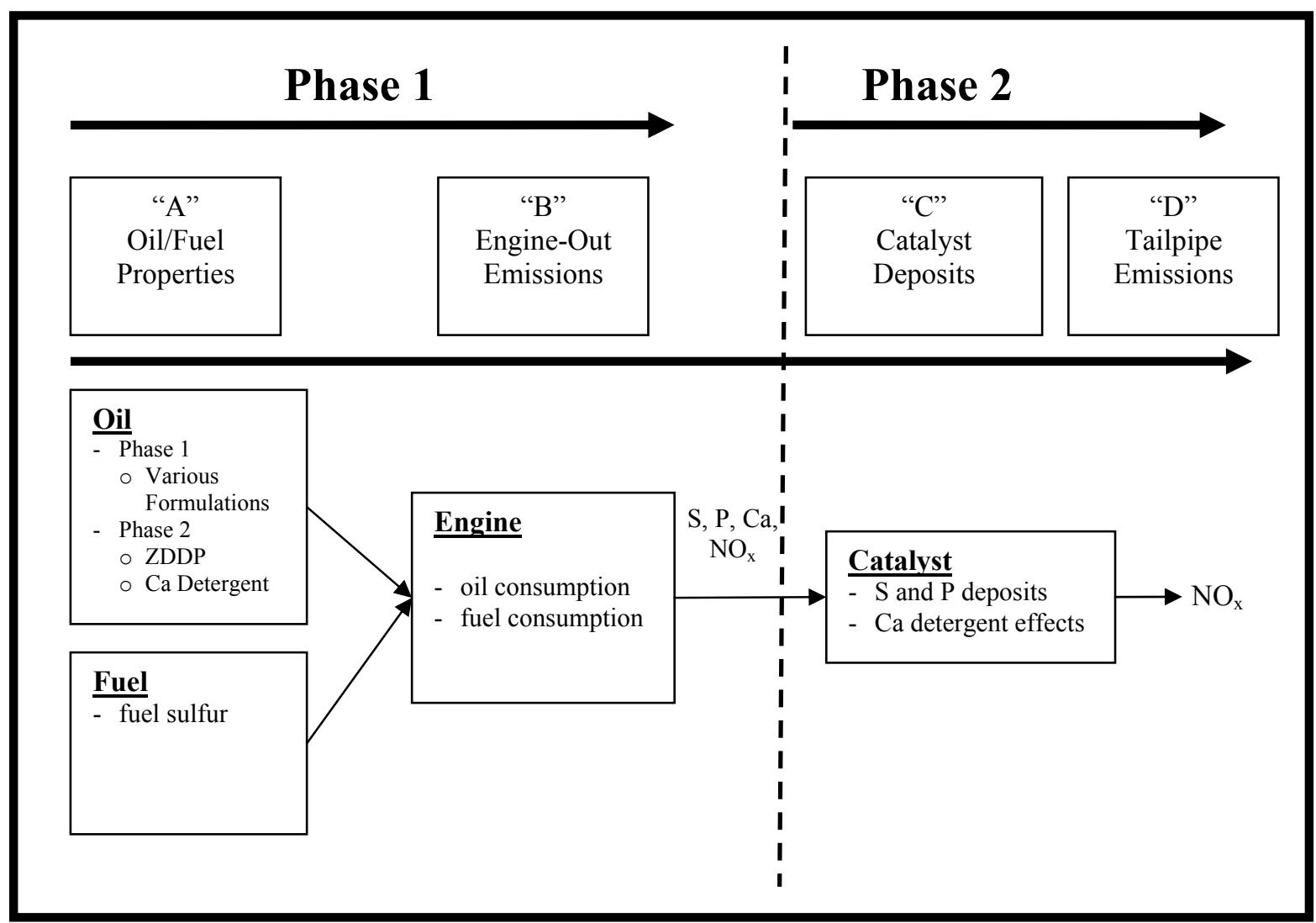

Figure 1. The lubricants project investigated the impacts of selected oil and fuel properties on the performance of the NAC

Phase 1 [4] demonstrated that engine-out emissions of oil-derived elements (specifically sulfur, phosphorus, and calcium) correlate well with the levels of those elements found in common lubricants and fuels. However, there was evidence, especially from tests with nonstandard lubricant formulations, that the source of the elements in the oil (base stock, detergent, wear additives) can affect the relationship between the elemental composition of the lubricant and the corresponding engine-out emissions. We also learned that lubricant properties have minimal effects (+/- 10 to $20 \%)$ on engine-out $\mathrm{NO}_{\mathrm{x}}$ levels. To achieve the Phase 2 objectives of evaluating the impacts of oil-derived emissions on the condition and performance of the catalyst, a series of study questions were developed to guide the experimental design and data analysis. They are organized into the following categories:

\section{Exposure of the Catalyst to Engine-Out Emissions (A vs. B)}

This area focuses on using mass balance methods to predict lubricant-and fuel-derived emissions of sulfur, phosphorus, and ash components that might affect catalyst performance.

Q1.1 What are the engine-out emissions of sulfur, phosphorus, and ash components (zinc and calcium) using each of the oils tested?

Q1.2 What was the total exposure of the test catalysts to these elements during 400 hours of aging? 


\section{Effects of Engine-Out Emissions on Catalyst Deposits (B vs. C)}

These questions address the relationship between engine-out emissions and the measured deposits of sulfur, phosphorus, and ash components on the used catalysts. These measurements were conducted by the catalyst supplier at the conclusion of the project.

Q2.1 What is the relationship between the catalyst exposures to sulfur, phosphorus, and ash components and the amount of these elements deposited on the catalysts?

Q2.2 How do the levels of deposits vary across the length of the catalysts?

Q2.3 Does the level of detergent in the lubricant affect the amount of sulfur or phosphorus that is deposited on the catalyst?

Q2.4 Does the type of calcium detergent affect the amount of sulfur and phosphorus deposited on the catalyst?

\section{Effects of Engine-Out Emissions on Catalyst Performance (B vs. D)}

This area addresses attempts to establish empirical relationships between lubricant properties and catalyst performance, as measured by $N O_{x}$ reduction efficiency (NRE).

Q3.1 How does the catalyst performance vary as a function of total exposures to sulfur, phosphorus, and calcium?

Q3.2 Do other oil properties provide a better fit to the performance measures? 


\section{Effects of Sulfur and Phosphorus Deposits on Catalyst Performance (C vs. D)}

This question focuses on the more direct relationship between the properties of the deposits found on the catalyst and the catalyst's performance during aging.

Q4.1 How does the catalyst performance vary as a function of the level of sulfur, phosphorus, and calcium deposits on the catalyst?

\section{Relative Effects of Lubricants and Fuels}

These questions address the relative contributions of the lubricant and fuel to the deposition of sulfur on the catalyst and observed changes in NRE.

Q5.1 How do lubricant contributions to engine-out sulfur emissions and the sulfur deposits on the catalysts compare to those attributable to 15-ppm sulfur fuel?

Q5.2 How does the degradation in NRE due to lubricant properties compare to the degradation that occurs with 15-ppm sulfur fuel? 


\section{Section 2: Technical Approach}

The technical approach is presented in two parts. Section 2.1 describes the experimental design; and Section 2.2 describes the laboratory procedures, and the data handling and statistical analysis methods.

\subsection{Experimental Design}

This section describes the selection of test hardware (engine and emission control system), fuels, emissions and engine performance measurements, durability test procedures, and the matrix of tests performed.

\subsubsection{Engine Selection}

A 2003 Cummins ISB engine was used in this study. The engine is direct-injected, electronically controlled, turbocharged, and aftercooled, with a displacement of 5.9L in an inline six-cylinder configuration with four valves per cylinder. The engine is also equipped with cooled exhaust gas recirculation, a variable geometry turbocharger, and a common-rail fuel injection system. The engine produces $224 \mathrm{~kW}(300 \mathrm{hp})$ at $2500 \mathrm{rpm}$.

This engine meets the applicable pull-ahead 2004 on-highway EPA standards of $2.5 \mathrm{~g} / \mathrm{bhp} \mathrm{hr}$ $\mathrm{NO}_{\mathrm{x}}+$ non-methane hydrocarbons and $0.1 \mathrm{~g} /$ bhp particulate matter (PM).

\subsubsection{Emissions Control Hardware}

The emission control system consisted of a single NAC. The catalyst, state-of-the-art at the time of testing, was $7 \mathrm{~L}$ in volume (9.5 inches diameter $\times 6$ inches length) with 400 cell per square inch (cpsi) cell density and 7 mil wall thickness. All catalysts provided to the APBF-DEC studies were provided in-kind by member companies of MECA.

\subsubsection{Test Fuel}

All tests were conducted using an ultra-low sulfur diesel fuel prepared for use in the APBF-DEC studies as well as studies from the predecessor DECSE project. The fuel properties (Table 2) are typical of on-road diesel fuel currently on the market with the exception of sulfur content $(0.6$ $\mathrm{ppm})$. One test was conducted with this base fuel doped with sulfur compounds at a concentration of $15 \mathrm{ppm}$. 
Table 2. Test Fuel Properties

\begin{tabular}{|c|c|c|}
\hline Fuel Property & $\begin{array}{c}\text { ASTM } \\
\text { Method }\end{array}$ & Value \\
\hline Density $\left(\mathrm{kg} / \mathrm{m}^{3}\right)$ & D4052 & 826.2 \\
\hline Viscosity @ $40^{\circ} \mathrm{C}\left(\mathrm{mm}^{2} / \mathrm{s}\right)$ & D445 & 2.3 \\
\hline \multicolumn{3}{|l|}{ Distillation } \\
\hline IBP $\left({ }^{\circ} \mathrm{C}\right)$ & D86 & 180 \\
\hline $10 \%$ recovery $\left({ }^{\circ} \mathrm{C}\right)$ & D86 & 203 \\
\hline $20 \%$ recovery $\left({ }^{\circ} \mathrm{C}\right)$ & D86 & 219 \\
\hline $30 \%$ recovery $\left({ }^{\circ} \mathrm{C}\right)$ & D86 & 233 \\
\hline $40 \%$ recovery $\left({ }^{\circ} \mathrm{C}\right)$ & D86 & 244 \\
\hline $50 \%$ recovery $\left({ }^{\circ} \mathrm{C}\right)$ & D86 & 251 \\
\hline $60 \%$ recovery $\left({ }^{\circ} \mathrm{C}\right)$ & D86 & 257 \\
\hline $70 \%$ recovery $\left({ }^{\circ} \mathrm{C}\right)$ & D86 & 265 \\
\hline $80 \%$ recovery $\left({ }^{\circ} \mathrm{C}\right)$ & D86 & 279 \\
\hline $90 \%$ recovery $\left({ }^{\circ} \mathrm{C}\right)$ & D86 & 312 \\
\hline FBP $\left({ }^{\circ} \mathrm{C}\right)$ & D86 & 352 \\
\hline Cloud point $\left({ }^{\circ} \mathrm{C}\right)$ & D2500 & -26 \\
\hline Pour point $\left({ }^{\circ} \mathrm{C}\right)$ & D97 & -23 \\
\hline Flash point, $\mathrm{PMCC}\left({ }^{\circ} \mathrm{C}\right)$ & D93 & 69 \\
\hline Sulfur (ppm) & D5453 & 0.6 \\
\hline Aromatics (vol. \%) & D1319 & 23.9 \\
\hline Olefins (vol. \%) & D1319 & 4.6 \\
\hline Saturates (vol. \%) & D1319 & 71.4 \\
\hline Aromatics (vol. \%) & D5186 & 26.9 \\
\hline Polyaromatics (vol. \%) & D5186 & 8.4 \\
\hline Non-aromatics (vol. \%) & D5186 & 64.7 \\
\hline Cetane number & D613 & 42.5 \\
\hline Cetane index & D976 & 51.5 \\
\hline
\end{tabular}

\subsubsection{Emissions Measurements and Analysis Methods}

Table 3 lists the gaseous emissions measurements and the corresponding instrumentation. No PM emissions were measured as part of this study.

Table 3. Emission Measurement Instrumentation

\begin{tabular}{|c|l|}
\hline Emission Measurement & \multicolumn{1}{c|}{ Instrument/Method } \\
\hline $\mathrm{NO}_{\mathrm{x}}$ & Chemiluminescence \\
\hline $\mathrm{CO}$ & NDIR \\
\hline $\mathrm{CO}_{2}$ & NDIR \\
\hline $\mathrm{O}_{2}$ & Paramagnetic \\
\hline $\mathrm{HC}_{2}$ & Heated flame ionization detector \\
\hline $\mathrm{SO}_{2}$ & Pulsed fluorescence \\
\hline
\end{tabular}

\subsubsection{Durability Tests}

A total of eight 400-hour aging tests were conducted in this study. An aging cycle consisting of six steady-state modes was developed to cycle the engine and catalyst through a variety of exhaust temperatures and space velocities. Each steady-state mode was held for 30 minutes prior to transitioning to the next mode. Regeneration frequency varied by mode and ranged from every 25 to every 60 seconds. 
After each test, the engine oil was changed to the next test oil using a triple-flush procedure to avoid any carryover effects from previous tests. The engine oil was also changed after 200 hours of operation (the midpoint of the aging test) because some of the test oils contained low levels of anti-wear and detergent additives. A gravimetric procedure was used to track oil consumption rate during all of the aging tests. Oil samples were taken from the engine at 50-hour intervals, and then analyzed for metals, soot content, total base number (TBN), and viscosity.

\subsubsection{Test Matrix}

Due to the time and expense involved in aging tests, the selection of test lubricants was not as extensive or as robust as was tested in Phase 1. All lubricants tested in Phase 2 were blended with Group II base oil by a single additive supplier. The properties of the lubricants selected for testing are illustrated in Figure 2. By varying the levels of ZDDP and detergent additives, six distinct test lubricants were blended. Four of the test oils (A through D) were blended using a calcium sulfonate detergent. Levels of ZDDP and detergent were varied to achieve the four possible combinations illustrated in Figure 2. Two additional test oils were formed with the high levels of ZDDP and calcium detergent, except they were blended with calcium salicylate (E) and calcium phenate (F) detergents. Five of the six lubricant formulations were tested once each in 400-hour durability tests using 0.6-ppm sulfur DECSE fuel. The low-ZDDP/low-calcium detergent lubricant (A) was tested twice with the 0.6-ppm sulfur fuel and once with a 15-ppm sulfur DECSE fuel. 


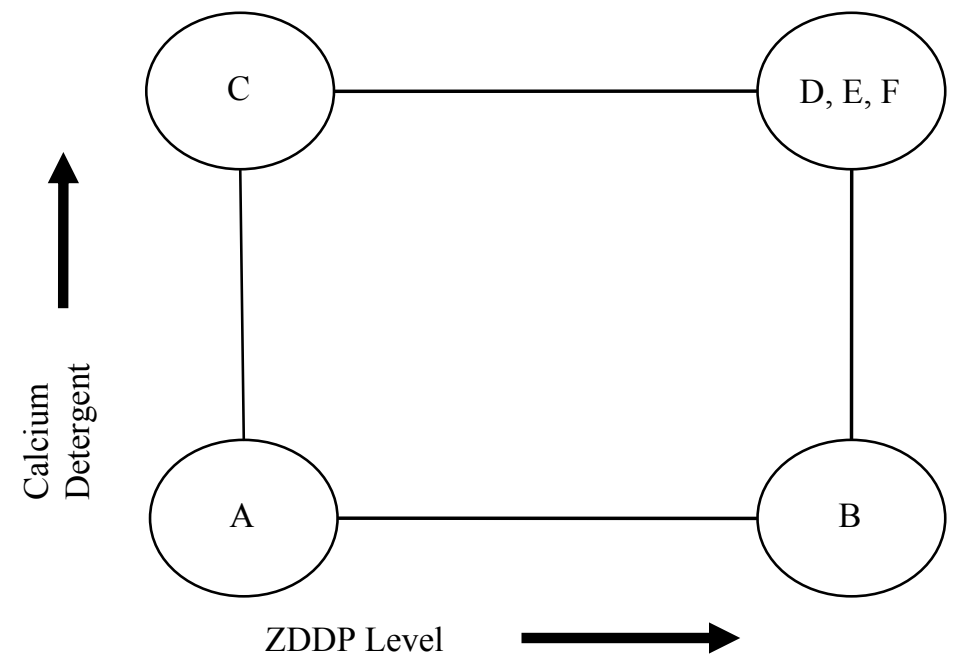

Figure 2. Lubricants selected for testing in phase 2 (Lubricants $A$ through $D$ contain calcium sulfonate detergents, and lubricants $E$ and $F$ contain calcium salicylate and calcium phenate detergents, respectively.)

The testing order specified in the test matrix (Table 4) attempted to separate tests with similar detergent and ZDDP levels. For example, test oil A (the only replicate test) was the first and seventh test performed. Oils D, E, and F (each with high levels of detergent and ZDDP) were separated by the low-detergent/high-ZDDP oil (B) and high-detergent/low-ZDDP oil (C). The eighth test was performed with oil A but with fuel doped to 15-ppm sulfur.

Table 4. Test Matrix

\begin{tabular}{|c|c|c|c|c|c|}
\hline \multirow{2}{*}{$\begin{array}{c}\text { Test } \\
\text { Number }\end{array}$} & \multirow[b]{2}{*}{ Lubricant ID ${ }^{\mathrm{a}}$} & \multirow{2}{*}{$\begin{array}{l}\text { ZDDP } \\
\text { Level }\end{array}$} & \multicolumn{2}{|c|}{ Detergent } & \multirow{2}{*}{$\begin{array}{l}\text { Fuel } \\
\text { Sulfur } \\
\text { (ppm) }\end{array}$} \\
\hline & & & Level & Type $^{b}$ & \\
\hline 1 & $A$ & Low & Low & Sulfonate & 0.6 \\
\hline 2 & $E$ & High & High & Salilcylate & 0.6 \\
\hline 3 & $\mathrm{~B}$ & High & Low & Sulfonate & 0.6 \\
\hline 4 & $\mathrm{~F}$ & High & High & Phenate & 0.6 \\
\hline 5 & C & Low & High & Sulfonate & 0.6 \\
\hline 6 & $\mathrm{D}$ & High & High & Sulfonate & 0.6 \\
\hline 7 & $A$ & Low & Low & Sulfonate & 0.6 \\
\hline 8 & $A$ & Low & Low & Sulfonate & 15.0 \\
\hline
\end{tabular}

a. Additives were blended in Group II base oil.

b. All detergents were calcium based.

Table 5 contains the measured properties of the test oils. Ash and sulfur were measured by the oil supplier prior to shipment, and the remaining properties were measured from samples taken from 
the oil drums at the time of the tests. Figure 3 displays pair-wise plots of selected measured properties and the interdependence of certain key properties. As shown in Figure 3, the design space of the test oils, in terms of calcium and phosphorus, approximates the two-by-two factorial design established for levels of ZDDP and calcium detergent, as shown in Figure 2. Note that the levels of sulfur and phosphorus, sulfur and zinc, and phosphorus and zinc are highly correlated because they are all contained in the ZDDP molecule.

Table 5. Properties of Test Oils

\begin{tabular}{|c|c|c|c|c|c|c|c|c|}
\hline \multirow[b]{2}{*}{$\begin{array}{c}\text { Test } \\
\text { Number }\end{array}$} & \multirow[b]{2}{*}{$\begin{array}{c}\mathrm{Ash}^{\mathrm{a}} \\
(\%)\end{array}$} & \multirow[b]{2}{*}{$\begin{array}{c}\mathrm{S}^{\mathrm{a}} \\
(\mathrm{ppm})\end{array}$} & \multirow[b]{2}{*}{$\begin{array}{c}\text { Ca } \\
\text { (ppm) }\end{array}$} & \multirow[b]{2}{*}{$\begin{array}{c}\mathrm{P} \\
(\mathrm{ppm})\end{array}$} & \multirow[b]{2}{*}{$\begin{array}{c}\mathrm{Zn} \\
(\mathrm{ppm})\end{array}$} & \multirow{2}{*}{$\begin{array}{r}\mathrm{TBN} \\
(\mathrm{mg} \\
\mathrm{KOH} / \mathrm{g}) \\
\end{array}$} & \multicolumn{2}{|c|}{ Viscosity } \\
\hline & & & & & & & $\begin{array}{c}@ 100^{\circ} \mathrm{C} \\
(\mathrm{cSt})\end{array}$ & $\begin{array}{c}@ 40^{\circ} \mathrm{C} \\
\text { (cSt) }\end{array}$ \\
\hline 1 & 0.775 & 1695 & 1853 & 427 & 471 & 6.99 & 14.9 & 111.3 \\
\hline 2 & 1.522 & 2928 & 3258 & 1210 & 1320 & 12.34 & 15.0 & 111.9 \\
\hline 3 & 1.131 & 3980 & 2050 & 1430 & 1590 & 7.3 & 15.0 & 111.9 \\
\hline 4 & 1.316 & 4195 & 3160 & 1340 & 1520 & 10.6 & 15.0 & 112.5 \\
\hline 5 & 1.310 & 2228 & 3241 & 419 & 475 & 9.6 & 14.6 & 107.7 \\
\hline 6 & 1.497 & 4197 & 3518 & 1280 & 1480 & 10.2 & 14.7 & 109.1 \\
\hline 7 & 0.775 & 1695 & 2065 & 451 & 505 & 6.7 & 14.9 & 110.9 \\
\hline 8 & 0.775 & 1695 & 2329 & 483 & 546 & 8.7 & 14.9 & 110.9 \\
\hline
\end{tabular}

a. Ash and sulfur were measured by the supplier. All other properties were measured using samples taken from the drum prior to the aging test. 

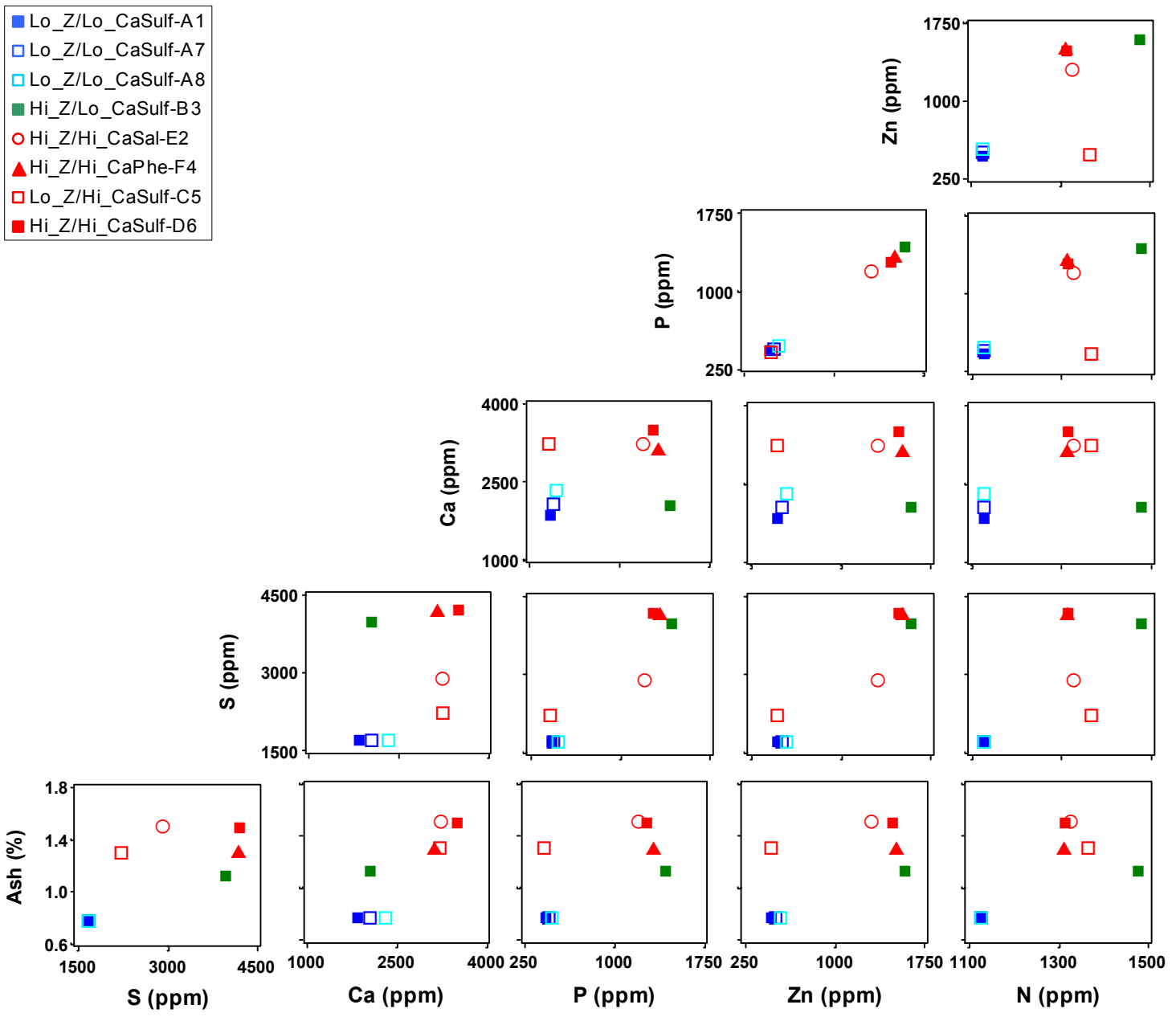

Figure 3. Pair-wise plots of measured properties of test oils

\subsection{Experimental Procedures}

\subsubsection{Laboratory Setup}

Analytical Engineering, Inc., installed the engine and emission control hardware in a test cell at its Columbus, Indiana, facility. Additional details regarding the test hardware as well as the sampling and analysis devices, and procedures are provided in the following sections.

\subsubsection{Performance Evaluation Procedures}

Catalyst performance evaluations were conducted periodically throughout the aging tests. This sequence of tests was conducted at the start of test, and every 100 hours thereafter. $\mathrm{NO}_{\mathrm{x}}$ adsorber outlet gas composition was continuously recorded at 1 hertz in order to monitor the system performance. Outlet conditions were measured with a five-gas emissions rack. Engineout conditions were recorded at the zero hour point to characterize the baseline engine emissions with the full emissions rack. Throughout the test, engine-out conditions were monitored for $\mathrm{NO}_{\mathrm{x}}$ and oxygen concentrations with a zirconia $\mathrm{NO}_{\mathrm{x}}$ sensor. If there were any significant changes in 
the engine-out emissions, a full emissions rack was utilized to determine the cause of any change. The general procedure was as follows:

1. Prior to the start of each performance evaluation, calibrate each of the five gas analyzers according to standard procedures.

2. Connect a heated sample line to the sample port on the exhaust stack in the test cell. Ensure that the heated sample line and heated filter are maintained at $300^{\circ} \mathrm{F}\left(149^{\circ} \mathrm{C}\right)$.

3. Verify that all data channels will be data logged at a 1-hertz sampling rate upon test initiation.

4. Record the barometric pressure and relative humidity of the intake air.

5. Review the last set of six mode data generated prior to shutting down the engine. Ensure that engine-out $\mathrm{NO}_{\mathrm{x}}$ and lambda have not changed more than $5 \%$ at each mode before starting the test.

6. Turn on the hydrocarbon (HC) dosing system and ensure that it is functioning properly.

7. Confirm that the bypass leg is closed and the $\mathrm{NO}_{\mathrm{x}}$ adsorber leg is open.

8. Start the engine and warm it up.

9. Begin data logging and start automatic test script for performance testing. (Note: The automatic test script was written to run each mode automatically for a prescribed period of time, generally 30 minutes per mode. The HC dosing system is active, using the same regeneration strategy as that employed during the durability portion of this testing.)

10. Shut down engine.

11. Report the following data:

a. Plot 1-second data at each mode ( 0 hour catalyst-out, 100 hour performance)

i. $\mathrm{NO}_{\mathrm{x}}, \mathrm{ppm}$

ii. $\mathrm{NO}_{\mathrm{x}}$, humidity corrected ppm

iii. NRE

iv. Carbon monoxide (CO), ppm

v. Carbon dioxide $\left(\mathrm{CO}_{2}\right), \%$

vi. $\mathrm{HC}, \mathrm{ppm}$

vii. $\mathrm{O}_{2}, \%$

b. Report integrated brake-specific values for each mode (grams/bhp-hr) pre- and post-desulfation

i. $\mathrm{NO}_{\mathrm{x}}$

ii. Humidity corrected $\mathrm{NO}_{\mathrm{x}}$

iii. $\mathrm{CO}$

iv. $\mathrm{HC}$ 


\subsubsection{Emissions Sampling and Analysis Procedures}

Figure 4 provides a schematic diagram for the exhaust emissions sampling and measurement system. Engine exhaust was routed from the turbine outlet toward the emission control system. Bypass valves allowed for the exhaust flow to be directed either through the NAC or - when engine-out measurements were desired - the flow could be bypassed around the catalyst. A single heated sample line drew exhaust from downstream of the catalyst to the emissions bench for characterization. $\mathrm{NO}_{\mathrm{x}}$ sensors were installed in the turbine outlet as well as downstream of the catalyst for continuous measurement of catalyst performance. Analysis procedures were described in Section 2.1.4.

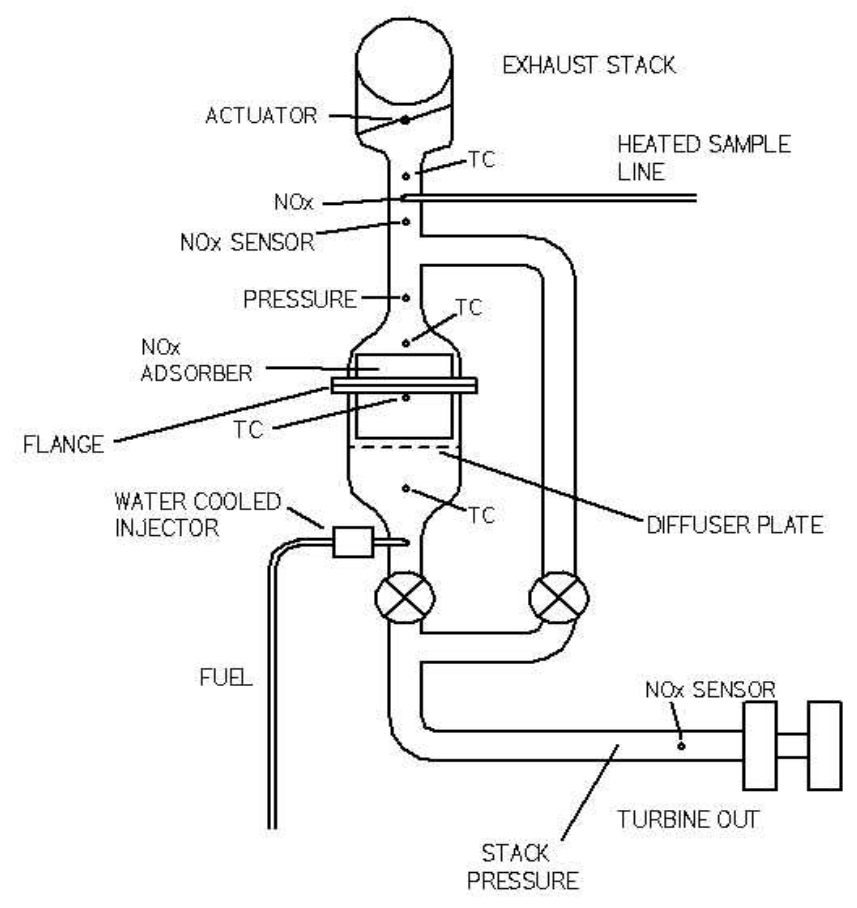

Figure 4. Emissions sampling and measurement schematic

\subsubsection{Data Handling}

Data provided by the test laboratory included second-by-second and integrated measurements of $\mathrm{NO}_{\mathrm{x}}, \mathrm{HC}, \mathrm{CO}$, and $\mathrm{CO}_{2}$, as well as measures of various engine performance parameters. The laboratory also measured sulfur dioxide $\left(\mathrm{SO}_{2}\right)$ emissions using pulsed fluorescence, but the $\mathrm{SO}_{2}$ levels were so low that they could not be reliably measured. The laboratory prepared summary reports containing average brake-specific gaseous emissions ( $\mathrm{g} / \mathrm{bhp}-\mathrm{hr}$ ) for each mode of the sixmode, steady-state test cycle as well as the weighted average (composite) emissions across the six modes.

Prior to conducting the statistical analysis, a data review was conducted to ensure data completeness and accuracy. After comparing the data received with the data collection plan, the data were stored in a controlled database. Changes, updates, and corrections were carefully 
monitored and controlled. To identify gross outliers (unusual and unexplained emissions results) and unexplained variations or trends associated with laboratory procedures, plots of emission data versus time were prepared and shared with the laboratories and the technical committee.

Lists of outliers identified from the outlier analysis were sent to the laboratory with instructions to check for clerical errors, equipment failures, or other external factors that could explain the deviation in results. Clerical errors were corrected and outliers due to known problems were corrected whenever possible. If the data could not be corrected, but the outliers were found to be associated with documented testing or measurement issues, they were eliminated from the analysis.

\subsubsection{Statistical Analysis and Modeling}

The statistical analysis approaches to address the study questions are described below.

\section{Exposure of the Catalyst to Engine-Out Emissions (A vs. B)}

Q1.1 What are the engine-out emissions of sulfur, phosphorus, and ash components (zinc and calcium) using each of the oils tested?

Q1.2 What was the total exposure of the test catalysts to these elements during 400 hours of aging?

The method for addressing study questions Q1.1 and Q1.2 was straightforward application of material balance equations. For each of the oils tested in Phase 2, engine-out emissions of sulfur, phosphorus, zinc, and calcium were estimated using the measured concentrations of these elements in the oil and fuel, as well as the oil and fuel consumption rates. Phase 1 results demonstrated that emission levels are highly correlated with the elemental composition of the oil and fuel, but the recovery rates can vary depending on the particular element and the duration of the test. The total exposure (grams of sulfur, phosphorus, zinc, or calcium per liter of catalyst) was determined from the engine-out emissions, duration of the test (400 hours), and volume of the catalyst.

\section{Effects of Engine-Out Emissions on Catalyst Deposits (B vs. C)}

Q2.1 What is the relationship between the catalyst exposures to sulfur, phosphorus, and ash components and the amount of these elements deposited on the catalysts?

Q2.2 How do the levels of deposits vary across the length of the catalysts?

Q2.3 Does the level of calcium in the lubricant affect the amount of sulfur or phosphorus that is deposited on the catalyst?

Q2.4 Does the type of calcium detergent affect the amount of sulfur and phosphorus deposited on the catalyst? 
The concentration (grams/liter) of sulfur, phosphorus, calcium, and zinc deposited on the catalyst after 400 hours of testing was determined by calculating the average concentrations measured in three samples taken from the front, middle, and rear of the catalyst at the conclusion of the test. The samples were analyzed using the Uniquant ${ }^{\circledR} \mathrm{X}$-ray fluorescence (XRF) method. The relationships between the measured deposits of sulfur and phosphorus and the predicted exposures were analyzed using the following multiple regression models:

Model 1: $\left(S_{\text {Deposited }}\right)_{i}=\beta_{0}+\beta_{1} \times\left(S_{\text {Exposed }}\right)_{i}+\beta_{2} \times\left(C_{\text {Exposed }}\right)_{i}+e_{i}$

Model 2: $\left(P_{\text {Deposited }}\right)_{i}=\beta_{0}+\beta_{1} \times\left(P_{\text {Exposed }}\right)_{i}+\beta_{2} \times\left(C_{\text {Exposed }}\right)_{i}+e_{i}$

Model 3: $\left(S_{\text {Deposited }}+P_{\text {Deposited }}\right)_{i}=\beta_{0}+\beta_{1} \times\left(S_{\text {Exposed }}+P_{\text {Exposed }}\right)_{i}+\beta_{2} \times\left(C a_{\text {Exposed }}\right)_{i}+e_{i}$

where $\beta_{0}$ is an overall intercept; $\beta_{1}$ represents the slope with respect to sulfur, phosphorus, or sulfur plus phosphorus $(\mathrm{S}+\mathrm{P})$ exposure; $\beta_{2}$ represents the slope with respect to calcium exposure; and $\mathrm{e}_{\mathrm{i}}$ is the error associated with ith test. Hypotheses tests were performed to determine if there were significant effects of calcium, given the presence of sulfur, phosphorus, or $(\mathrm{S}+\mathrm{P})$ in the model.

Because only one test was performed on each of the oils formulated with salicylate and phenate detergents, it was not possible to estimate simultaneously the effects of detergent type (sulfonate, salicylate, phenate) and exposure levels of calcium, sulfur, and phosphorus on the quantities of sulfur and phosphorus deposited on the catalysts. Instead we used a compromise approach by performing regression analysis on two different sets of data and compared the results. The two data sets came from: (1) all tests with non-doped fuel, and (2) only those tests with non-doped fuel and lubricants containing calcium sulfonate.

Simple descriptive methods were used to look for trends in the measured deposits of calcium, sulfur, and phosphorus along the length of the catalysts.

\section{Effects of Engine-Out Emissions on Catalyst Performance (B vs. D)}

Q3.1 How does the catalyst performance vary as a function of total exposures to sulfur, phosphorus, and calcium?

Q3.2 Do other oil properties provide a better fit to the performance measures?

In order to identify performance measures that are sensitive to the effects of lubricant-derived emissions, several different measures based on NRE or changes in NRE at various time points during the test were explored. Analyses were performed using the actual measured NRE at individual time points as well as estimated performance measures obtained from statistical models of NRE versus aging hours. The latter approach produced more consistent results. In particular we examined the relationships between catalyst exposures to sulfur, phosphorus, and calcium from engine-out emissions and the following performance measures:

- Predicted NRE at 200, 300, and 400 hours

- Change in predicted NRE through 200, 300, and 400 hours. 
The change in predicted NRE was estimated using the difference between the predicted values of NRE at 10 and 200 hours; 10 and 300 hours; or 10 and 400 hours.

Scatter plots and multiple regression analyses of each performance measure versus levels of phosphorus, sulfur, and calcium exposures were used to address the two questions listed above. The analysis of engine-out emissions versus catalyst performance is divided into two parts. First we examined the combined effect of S+P and calcium emissions; then we looked at the combined effects of phosphorus and calcium emissions. The following regression models were applied to each performance measure:

$$
\begin{aligned}
& \text { Model 4: Performance Measure }{ }_{i}=\beta_{0}+\beta_{1} \times\left(\mathrm{S}_{\text {Exposed, }}+\mathrm{P}_{\text {Exposed }},\right)_{\mathrm{i}}+\mathrm{e}_{\mathrm{i}} \\
& \text { Model 5: Performance Measure }{ }_{i}=\beta_{0}+\beta_{2} \times\left(\mathrm{Ca}_{\text {Exposed }}\right)_{\mathrm{i}}+\mathrm{e}_{\mathrm{i}} \\
& \text { Model 6: Performance Measure } e_{i}=\beta_{0}+\beta_{1} \times\left(\mathrm{S}_{\text {Exposed }}+\mathrm{P}_{\text {Exposed }}\right)_{i}+\beta_{2} \times\left(\mathrm{Ca}_{\text {Exposed }}\right)_{i}+\mathrm{e}_{i} \\
& \text { Model 7: Performance Measure } \mathrm{i}_{\mathrm{i}}=\beta_{0}+\beta_{1} \times\left(\mathrm{P}_{\text {Exposed }_{\mathrm{i}}}\right)_{\mathrm{i}}+\mathrm{e}_{\mathrm{i}} \\
& \text { Model 8: Performance Measure }{ }_{i}=\beta_{0}+\beta_{2} \times\left(\mathrm{Ca}_{\text {Exposed }}\right)_{\mathrm{i}}+\mathrm{e}_{\mathrm{i}} \\
& \text { Model 9: Performance Measure } e_{i}=\beta_{0}+\beta_{1} \times\left(\mathrm{P}_{\text {Exposed }}\right)_{i}+\beta_{2} \times\left(\mathrm{Ca}_{\text {Exposed }}\right)_{i}+e_{i}
\end{aligned}
$$

where $\beta_{0}$ is an overall intercept; $\beta_{1}$ represents the slope with respect to phosphorus or $\mathrm{S}+\mathrm{P}$ exposure; $\beta_{2}$ represents the slope with respect to calcium exposure; and $e_{i}$ is the error associated with ith test. Hypotheses tests were performed to determine if there were significant effects of phosphorus, $\mathrm{S}+\mathrm{P}$, and calcium exposures on the performance measure.

Stepwise multiple regression analysis was used to investigate when other oil properties provided a better fit to the performance measures. The backward selection approach was used to generate a model containing all significant variables. A significance level of 0.05 was used to retain properties in the model. The properties considered for inclusion in the final model are: sulfur, calcium, phosphorus, zinc, and nitrogen. This same approach was applied to the principal component scores for each oil. When the characteristics of the data (oil properties in this case) are highly correlated, principal component analysis is used to obtain independent linear combinations of the original oil properties that represent the major sources of variability in the data.

\section{Effects of Sulfur and Phosphorus Deposits on Catalyst Performance (C vs. D)}

Q4.1 How does the catalyst performance vary as a function of the level of sulfur, phosphorus, and calcium deposits on the catalyst?

The analytical approach for addressing Q4.1 is almost identical to the approach used to address Q3.1, except the exposure measures are replaced with average deposits. The performance measures described above were used in this analysis. The following regression models were applied to each performance measure:

$$
\begin{array}{ll}
\text { Model 10: } & \text { Performance Measure } e_{i}=\beta_{0}+\beta_{1} \times\left(\mathrm{S}_{\text {Deposited }}+\mathrm{P}_{\text {Deposited }}\right)_{\mathrm{i}}+\mathrm{e}_{\mathrm{i}} \\
\text { Model 11: } & \text { Performance Measure }_{\mathrm{i}}=\beta_{0}+\beta_{2} \times\left(\mathrm{Ca}_{\text {Deposited }}\right)_{\mathrm{i}}+\mathrm{e}_{\mathrm{i}} \\
\text { Model 12: } & \text { Performance Measure }_{\mathrm{i}}=\beta_{0}+\beta_{1} \times\left(\mathrm{S}_{\text {Deposited }}+\mathrm{P}_{\text {Deposited }}\right)_{\mathrm{i}}+\beta_{2} \times\left(\mathrm{Ca}_{\text {Deposited }}\right)_{\mathrm{i}}+\mathrm{e}_{\mathrm{i}}
\end{array}
$$


Model 13: $\quad$ Performance Measure ${ }_{i}=\beta_{0}+\beta_{1} \times\left(\mathrm{P}_{\text {Deposited }}\right)_{\mathrm{i}}+\mathrm{e}_{\mathrm{i}}$

Model 14: $\quad$ Performance Measure ${ }_{i}=\beta_{0}+\beta_{2} \times\left(\mathrm{Ca}_{\text {Deposited }}\right)_{i}+\mathrm{e}_{\mathrm{i}}$

Model 15: $\quad$ Performance Measure ${ }_{i}=\beta_{0}+\beta_{1} \times\left(\mathrm{P}_{\text {Deposited }}\right)_{i}+\beta_{2} \times\left(\mathrm{Ca}_{\text {Deposited }}\right)_{\mathrm{i}}+\mathrm{e}_{\mathrm{i}}$

where $\beta_{0}$ is an overall intercept; $\beta_{1}$ represents the slope with respect to phosphorus or $\mathrm{S}+\mathrm{P}$ deposited on the catalysts; $\beta_{2}$ represents the slope with respect to calcium deposited on the catalysts; and $\mathrm{e}_{\mathrm{i}}$ is the error associated with ith test. Hypotheses tests were performed to determine if there were significant effects of phosphorus, $\mathrm{S}+\mathrm{P}$, and calcium deposits on the performance measure.

\section{Relative Effects of Lubricants and Fuel}

Q5.1 How do lubricant contributions to engine-out sulfur emissions and the sulfur deposits on the catalysts compare to those attributable to 15-ppm sulfur fuel?

Q5.2 How does the degradation in NRE due to lubricant properties compare to the degradation that occurs with 15-ppm sulfur fuel?

These questions were addressed by comparing various results from the two Lubricant $\mathrm{A}$ tests run with 0.6-ppm sulfur fuel with the single Lubricant A test run with 15-ppm sulfur fuel. The results of interest are the estimated engine-out emissions of sulfur, measured sulfur deposits on the aged catalyst, sulfur recovery (deposits divided by engine-out emissions), and NRE of the catalyst versus time. Because of the limited data, only simple descriptive methods were used to make these comparisons. 


\section{Section 3: Results}

The results of the study are organized into five parts according to the study questions presented in Section 1.2.

\subsection{Exposure of the Catalyst to Engine-Out Emissions}

This section presents results that characterize the lubricant- and fuel-derived emissions of sulfur, phosphorus, and ash components that are expected to affect catalyst performance. The following study questions are addressed:

Q1.1 What are the engine-out emissions of sulfur, phosphorus, and ash components (zinc and calcium) using each of the oils tested?

Q1.2 What was the total exposure of the test catalysts to these elements during 400 hours of aging?

Phase 1 findings demonstrated that lubricant-derived emissions of sulfur, phosphorus, and ash components (zinc and calcium) are highly correlated with properties of the lubricant. Therefore, a mass balance approach was used to estimate engine-out emissions for each of the oils tested in Phase 2. The calculations were based on the following parameters:

- Average oil consumption rate (lb/hr) during the 400-hour test

- Sulfur, phosphorus, and ash (zinc and calcium) contents (\%) of the test lubricants

- Fuel consumed in the engine and the dosing system (lb/bhp-hr)

- Sulfur content of the fuel (0.6 ppm or $15 \mathrm{ppm})$

- Average power (bhp) for the composite mode

- Duration of the test (hr).

Specifically, the following formula was used to calculate the engine-out emission rate for each element of interest:

Engine-Out Emissions ( $\mathrm{mg} / \mathrm{bhp} \mathrm{hr})$

$=$ Content in the Oil $(\%) \times$ Oil Consumption Rate $(\mathrm{lb} / \mathrm{hr}) \times 454000(\mathrm{mg} / \mathrm{lb}) /$ Power $(\mathrm{bhp})$

+ Content in the Fuel $(\mathrm{ppm}) \times$ Fuel Consumption Rate $(\mathrm{lb} / \mathrm{bhp} \mathrm{hr}) \times 454000(\mathrm{mg} / \mathrm{lb}) / 1000000$

It was assumed that the phosphorus, calcium, and zinc contents of the fuel were insignificant.

Table 6 displays the input parameters and estimated engine-out emissions of sulfur, phosphorus, and ash components for each of the oils tested. Total exposures (in $\mathrm{g}$ and $\mathrm{g} / \mathrm{liter}$ ) of the test catalysts to sulfur, phosphorus, and ash components during 400 hours of aging were also calculated. 
Table 6. Estimated Engine-Out Emissions and Total Exposures of Catalysts to Sulfur, Phosphorus, and Ash Components (Zinc and Calcium)

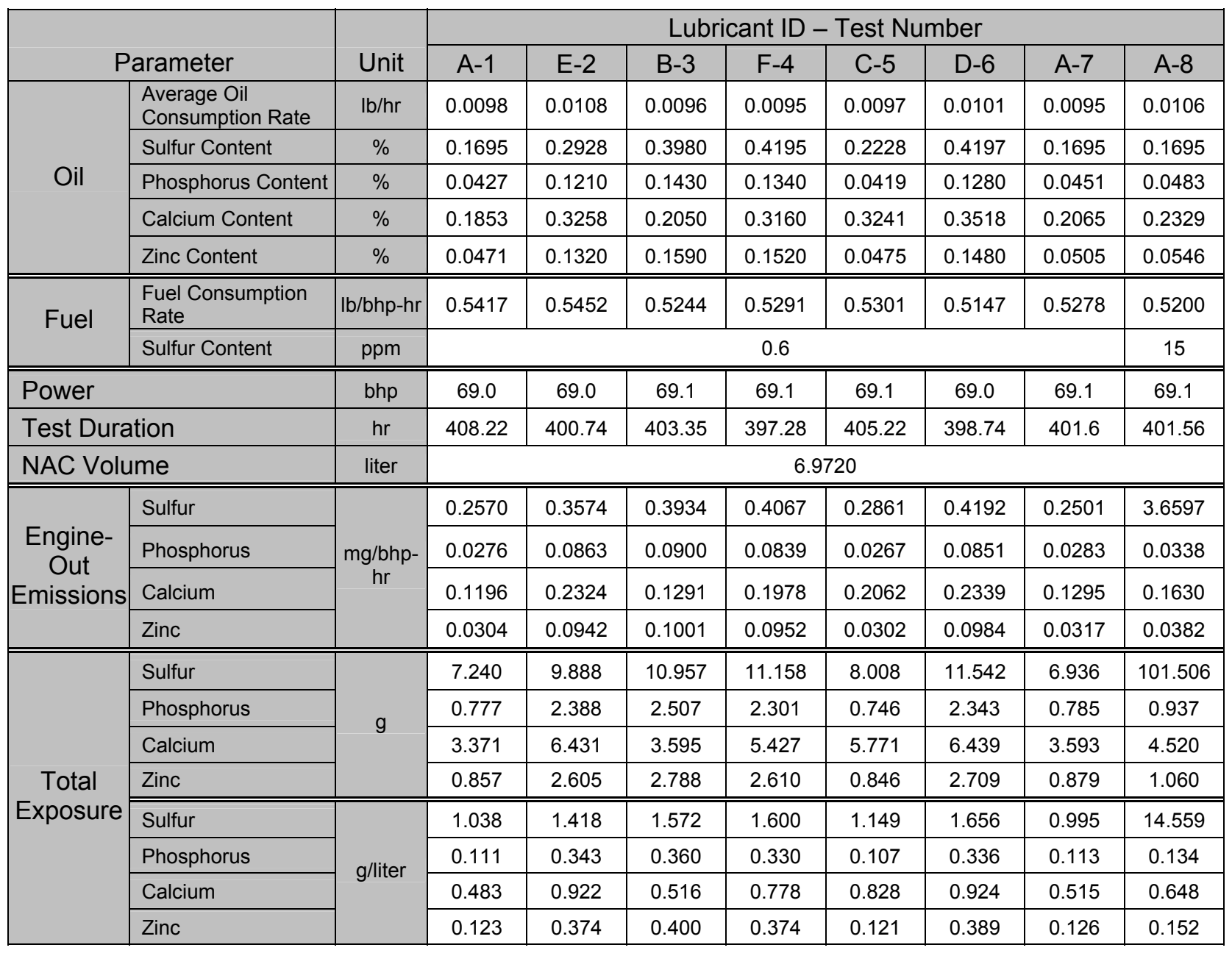

\subsection{Effects of Engine-Out Emissions on Catalyst Deposits}

This section addresses the relationship between engine-out emissions and the measured deposits of sulfur, phosphorus, and ash components on the used catalysts. The following study questions are addressed:

Q2.1 What is the relationship between the catalyst exposures to sulfur, phosphorus, and ash components and the amount of these elements deposited on the catalysts?

Q2.2 How do the levels of deposits vary across the length of the catalysts?

Q2.3 Does the level of calcium in the lubricant affect the amount of sulfur or P that is deposited on the catalyst? 
Q2.4 Does the type of calcium detergent affect the amount of sulfur and phosphorus deposited on the catalyst?

\section{Deposits versus Exposure}

Figure 5 displays plots of the average mass of various lubricant-derived components (sulfur, phosphorus, calcium) deposited on the catalysts versus the corresponding exposures. Because both sulfur and phosphorus are known to affect catalyst performance, we also compared the total deposits of $\mathrm{S}+\mathrm{P}$ with the corresponding total exposure. Zinc deposits on the catalysts were not detectable. Results from test number 8 (performed with 15-ppm sulfur fuel) are not shown in Figure 5. These results are discussed in Section 3.5.

Deposit levels ( $\mathrm{g} /$ liter) on the catalysts were calculated from the average of XRF measurements taken on samples extracted from the front, middle, and rear of the catalyst at the conclusion of testing. Because of the difficulty in calibrating the XRF measurements and the lack of precise tailpipe emissions, the recovery estimates should only be used for comparative analyses between tests. The absolute value of the recovery may not be accurate. The plots in Figure 5 suggest the following:

1. For tests with similar levels of sulfur exposed, low calcium sulfonate oils (tests 1, 3 , and 7) deposit more sulfur than oils with high calcium sulfonate detergent (tests 5 and 6). This pattern is also found for phosphorus and $\mathrm{S}+\mathrm{P}$.

2. Deposition of sulfur and phosphorus is higher with lubricants containing calcium salicylate and calcium phenate detergents (tests $2 \& 4$ ) than with the lubricant containing calcium sulfonate detergent and similar sulfur and phosphorus exposures (test 3 ).

Due to the limited number of tests, it is not feasible to draw firm conclusions based on these observations. However, later in this section these relationships are explored further using statistical models to address study questions Q2.3 and Q2.4. 

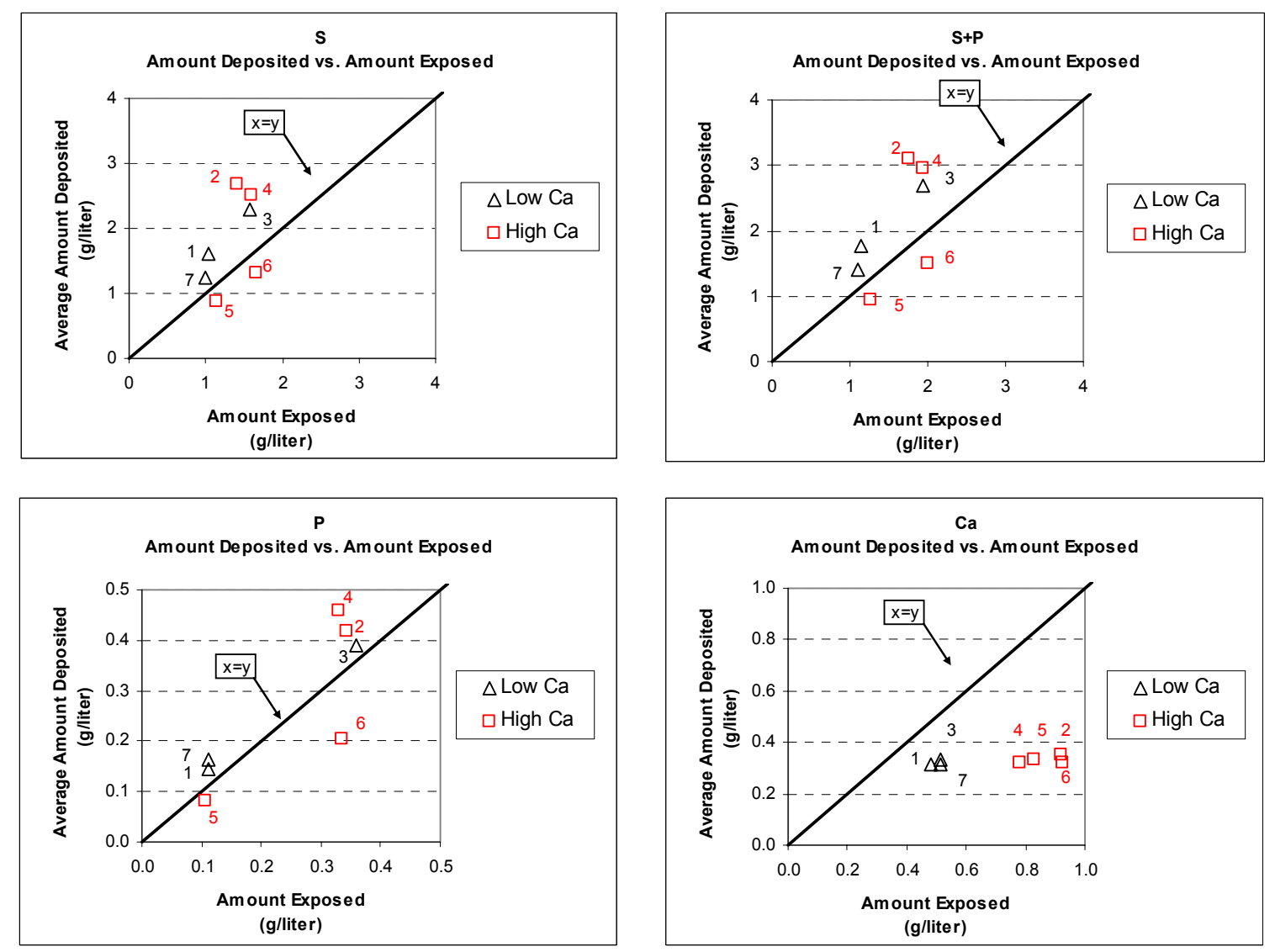

Note: The numbers in the plots refer to the Test Number shown in Table 4.

Figure 5. Comparisons of average sulfur, phosphorus, and calcium deposits as a function of estimated exposures

\section{Deposits along the Length of the Catalyst}

Figure 6 displays the measured concentrations of sulfur, phosphorus, and calcium deposited in the front, middle, and rear of the catalysts. It demonstrates that concentrations of sulfur and phosphorus decrease monotonically along the length of the catalyst. In general, $50 \%$ of the sulfur accumulated in the front of the catalyst, $30 \%$ in the middle, and $20 \%$ in the rear. A higher proportion (70\%) of the phosphorus accumulates in the front of the catalyst, while $20 \%$ and $10 \%$ accumulate in the middle and rear, respectively. 

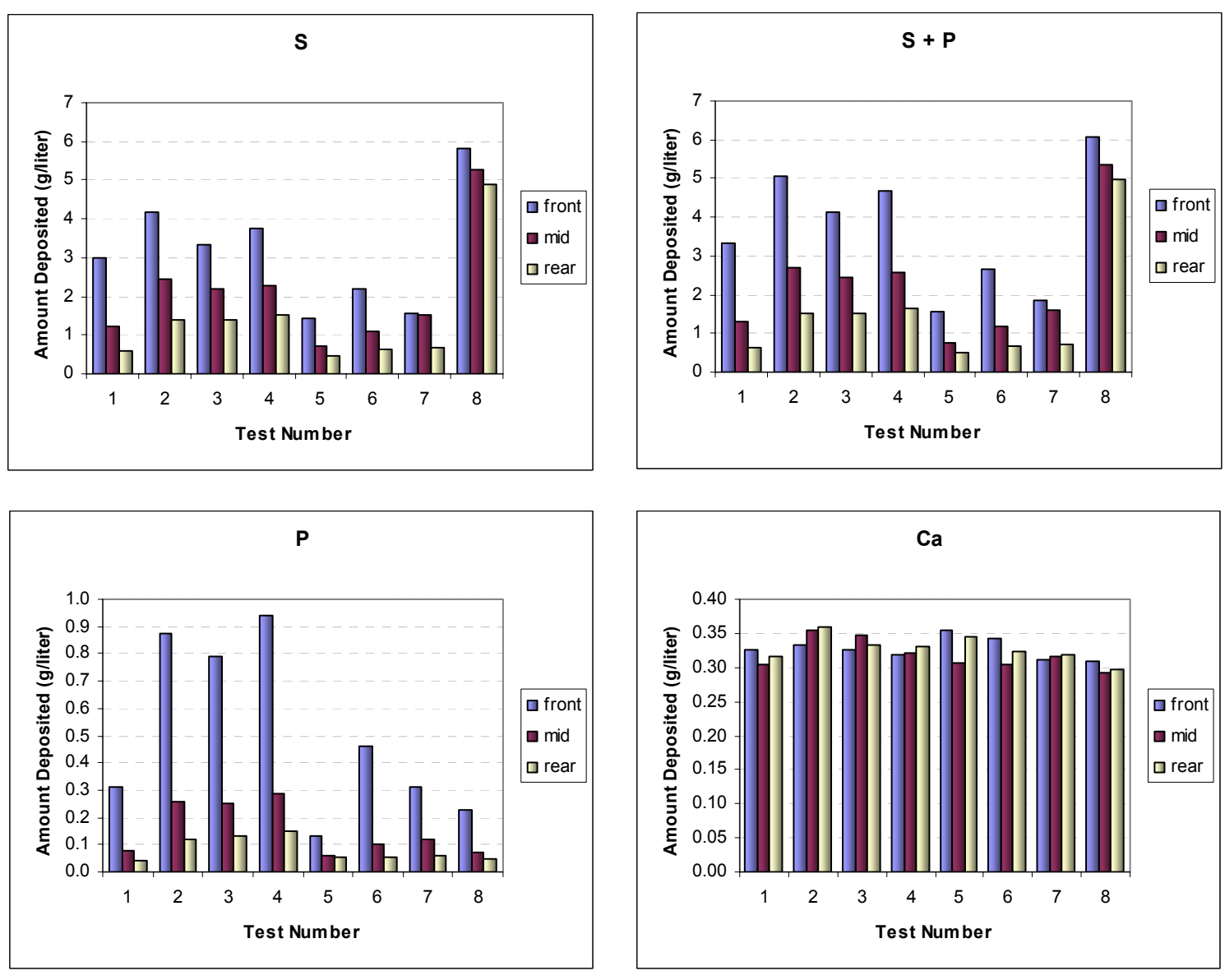

Figure 6. Sulfur, Phosphorus, $\mathrm{S}+\mathrm{P}$, and Calcium deposited at the front, middle, and rear of the catalyst

\section{Impact of the Type and Level of Calcium Detergent on the Amount of Sulfur and Phosphorus Deposits on the Catalyst}

Statistical analyses were performed to further explore the relationships between the total exposures of sulfur and phosphorus and the amounts of these elements deposited on the catalyst. The analysis also explores the impact of calcium detergent on this relationship. Ideally, we would perform the analysis on the entire set of data and simultaneously estimate the effects of exposures to calcium, phosphorus, and sulfur-along with the effects of detergent type (sulfonate, salicylate, phenate). However, because only one test each was performed with the salicylate and phenate detergents, it was not possible to isolate the effects of detergent type in this analysis. So, a compromise approach was used in which linear regression analysis was performed to establish the relationship between deposits and exposure using all of the test data. The analysis was then repeated using only data from tests performed on lubricants that contained calcium sulfonate detergent, and the models were compared to determine the best fit to the data. If the model fit is significantly improved when analyzing only the data from the sulfonate detergent tests, it suggests that detergent type is an important factor. Although this approach reduces the sample size to five tests, we are comparing results from tests that differ only in terms 
of the levels of sulfur, phosphorus, and $\mathrm{S}+\mathrm{P}$ in the test oil. Because Test Number 8 was the only test performed with doped fuel, it was excluded from this analysis.

As described in Section 2.2.5, the following statistical models were fit to each data set:

Model 1: $\left(S_{\text {Deposited }}\right)_{i}=\beta_{0}+\beta_{1} \times\left(S_{\text {Exposed }}\right)_{i}+\beta_{2} \times\left(C_{\text {Exposed }}\right)_{i}+e_{i}$

Model 2: $\left(P_{\text {Deposited }}\right)_{i}=\beta_{0}+\beta_{1} \times\left(P_{\text {Exposed }}\right)_{i}+\beta_{2} \times\left(C_{\text {Exposed }}\right)_{i}+e_{i}$

Model 3: $\left(S_{\text {Deposited }}+P_{\text {Deposited }}\right)_{i}=\beta_{0}+\beta_{1} \times\left(S_{\text {Exposed }}+P_{\text {Exposed }}\right)_{i}+\beta_{2} \times\left(C a_{\text {Exposed }) i}+e_{i}\right.$

Table 7 summarizes the results of the regression analyses. When all of the data are included, the R-squared correlations between exposure and amount of deposits of sulfur or total $\mathrm{S}+\mathrm{P}$ are relatively low (34\% to $46 \%$ ), and the estimated effects of exposure are not statistically significant. On the other hand, phosphorus exposure is a significant predictor $(p=0.029)$ of phosphorus deposits. The correlation is $74 \%$. However, with this data set, there is no statistical evidence that calcium levels affect the amount of deposits on the catalyst.

When tests involving the salicylate and phenate detergents are removed, the correlations increase to $97 \%$ and $98 \%$ and the effects of sulfur or phosphorus are either significant $(p<0.05)$ or nearly significant $(\mathrm{p}<0.10)$. Furthermore, the results indicate that the amount of calcium exposed has a significant effect on the amount of $\mathrm{S}+\mathrm{P}$ deposited on the catalysts. High-calcium sulfonate oils tend to reduce sulfur and phosphorus deposits compared to low-calcium sulfonate detergents containing the same levels of sulfur and phosphorus.

Table 7. Results of Regression Analyses to Establish Relationships between Exposure Levels and Measured Catalyst Deposits

\begin{tabular}{|c|c|c|c|c|c|c|c|c|}
\hline \multirow[b]{2}{*}{ Data Set } & \multirow[b]{2}{*}{$\begin{array}{l}\text { Response } \\
\text { Variable }\end{array}$} & \multirow[b]{2}{*}{$\begin{array}{c}\text { Explanatory } \\
\text { Variable }\end{array}$} & \multirow[b]{2}{*}{$\mathrm{N}$} & \multirow[b]{2}{*}{$\begin{array}{c}\mathrm{R}- \\
\text { square }\end{array}$} & \multicolumn{2}{|c|}{ S/P/(S+P) Slope } & \multicolumn{2}{|c|}{$\mathrm{Ca}_{\text {Exposed }}$ Slope } \\
\hline & & & & & $\begin{array}{l}\text { Estimate } \\
\text { (std err) }\end{array}$ & $\begin{array}{c}\mathrm{p}- \\
\text { value }\end{array}$ & $\begin{array}{l}\text { Estimate } \\
\text { (std err) }\end{array}$ & $p$-value ${ }^{a}$ \\
\hline \multirow{3}{*}{ All Tests } & $S_{\text {Deposited }}$ & $\begin{array}{l}\mathrm{S}_{\text {Exposed }} \& \\
\mathrm{Ca}_{\text {Exposed }} \\
\end{array}$ & 7 & $34 \%$ & $\begin{array}{l}1.674 \\
(1.19) \\
\end{array}$ & 0.256 & $\begin{array}{l}-0.882 \\
(1.685) \\
\end{array}$ & 0.628 \\
\hline & $\mathrm{P}_{\text {Deposited }}$ & $\begin{array}{l}P_{\text {Exposed }} \& \\
C a_{\text {Exposed }} \\
\end{array}$ & 7 & $74 \%$ & $\begin{array}{c}1.143^{b} \\
(0.344) \\
\end{array}$ & 0.029 & $\begin{array}{l}-0.163 \\
(0.215) \\
\end{array}$ & 0.492 \\
\hline & $(\mathrm{S}+\mathrm{P})_{\text {Deposited }}$ & $\begin{array}{l}(\mathrm{S}+\mathrm{P})_{\text {Exposed }} \\
\& \mathrm{Ca}_{\text {Exposed }} \\
\end{array}$ & 7 & $46 \%$ & $\begin{array}{c}1.637 \\
(0.899) \\
\end{array}$ & 0.158 & $\begin{array}{l}-1.151 \\
(1.814) \\
\end{array}$ & 0.560 \\
\hline \multirow{3}{*}{$\begin{array}{l}\text { Tests with } \\
\text { Calcium } \\
\text { Sulfonate } \\
\text { Detergent }\end{array}$} & $\mathrm{S}_{\text {Deposited }}$ & $\begin{array}{l}S_{\text {Exposed }} \& \\
\text { Caxposed }\end{array}$ & 5 & $97 \%$ & $\begin{array}{c}1.564 \\
(0.232)\end{array}$ & 0.066 & $\begin{array}{l}-2.594^{b} \\
(0.348)\end{array}$ & 0.018 \\
\hline & $P_{\text {Deposited }}$ & $\begin{array}{l}\mathrm{P}_{\text {Exposed }} \& \\
\mathrm{Ca}_{\text {Exposed }}\end{array}$ & 5 & $97 \%$ & $\begin{array}{l}0.861^{b} \\
(0.123)\end{array}$ & 0.025 & $\begin{array}{l}-0.311 \\
(0.077)\end{array}$ & 0.057 \\
\hline & $(\mathrm{S}+\mathrm{P})_{\text {Deposited }}$ & $\begin{array}{l}(\mathrm{S}+\mathrm{P})_{\text {Exposed }} \\
\& \mathrm{Ca}_{\text {Exposed }}\end{array}$ & 5 & $98 \%$ & $\begin{array}{c}1.336^{b} \\
(0.173)\end{array}$ & 0.037 & $\begin{array}{l}-2.818^{b} \\
(0.365)\end{array}$ & 0.016 \\
\hline
\end{tabular}

a The significance level ( $p$-value) associated with the effect of calcium is conditional on the presence of $S, P$, or $S+P$ in the model.

b Estimated slope is different from zero at the 0.05 level of statistical significance.

Another way to summarize these results is to calculate the recovery rates for sulfur and phosphorus (average $\mathrm{g} / \mathrm{l}$ deposited divided by average $\mathrm{g} / \mathrm{l}$ exposure) for each of the three groups of tests using low-calcium sulfonate detergents, high-calcium sulfonate detergents, and high- 
calcium salicylate or phenate detergents, respectively (Table 8). Because of the uncertainties in the calibration of the XRF method used to measure deposits on the catalysts, the recovery rates should only be used for comparison purposes. In this case we see that the recoveries of sulfur and phosphorus are between $119 \%$ and $143 \%$ with low calcium sulfonate oils, and between $64 \%$ and $78 \%$ for high-calcium sulfonate oils. These results are consistent with previous research, which demonstrated that higher levels of detergent in lubricants can help to temper the deactivation of automotive three-way catalysts [3].

The oils with high levels of calcium salicylate and calcium phenate detergents resulted in phosphorus and sulfur recoveries of $130 \%$ to $172 \%$, respectively. Without a more fundamental analysis, it is difficult to fully understand the nature of this synergy. One possible explanation is that the detergent is binding with the sulfur- and phosphorus-containing emissions, allowing them to pass through the catalyst without depositing on the catalyst. It is also possible that the sulfonate detergents are more effective at creating a passivating layer on the catalyst surface that prevents deposition of sulfur and phosphorus. These are important findings, but they need to be confirmed and explained by a more fundamental study of the mechanism.

Table 8. Comparisons of Recovery Rates

\begin{tabular}{|c|c|c|c|c|}
\hline & Test & \multicolumn{3}{|c|}{ Element } \\
\cline { 5 - 5 } Calcium Levels and Detergent Type & Numbers & $\mathrm{S}$ & $\mathrm{P}$ & $\mathrm{S}+\mathrm{P}$ \\
\hline Low CaSulf $(<2200 \mathrm{ppm})$ & $1,3,7$ & $143 \%$ & $119 \%$ & $140 \%$ \\
\hline High CaSulf $(>3100 \mathrm{ppm})$ & 5,6 & $78 \%$ & $64 \%$ & $76 \%$ \\
\hline High CaSal/CaPhe $(>3100 \mathrm{ppm})$ & 2,4 & $172 \%$ & $130 \%$ & $164 \%$ \\
\hline
\end{tabular}

The statistical analyses described above were intended to explore empirical relationships that support possible conclusions. Even with more extensive statistical analyses, it would be difficult to reach firm conclusions with only eight tests. In particular, it is not possible to estimate recovery rates and fully characterize the effects of detergent type, while at the same time assessing the validity of the distributional assumptions, testing the linearity of responses, and separating confounding effects (e.g., detergent type and calcium detergent level).

\subsection{Effects of Engine-Out Emissions on Catalyst Performance}

This section establishes empirical relationships between lubricant properties and catalyst performance, as measured by NRE. The following study questions are addressed:

Q3.1 How does the catalyst performance vary as a function of total exposures to sulfur, phosphorus, and calcium?

Q3.2 Do other oil properties provide a better fit to the performance measures? 
In order to determine a measure of catalyst performance that is sensitive to changes in engine-out emissions, we examined a variety of performance measures based on NRE or changes in NRE at various time points during the test. In particular we examined the relationships between engineout emissions and the following performance measures:

- Predicted NRE at 200, 300, and 400 hours

- Change in predicted NRE through 200, 300, and 400 hours.

Predicted NRE was estimated from a simple linear regression model of NRE versus time. The change in predicted NRE was estimated using the difference between the predicted values of NRE at 10 and 200 hours, 10 and 300 hours, or 10 and 400 hours.

\section{Impacts of Sulfur, Phosphorus, and Calcium Exposure}

The analysis of engine-out emissions versus catalyst performance is divided into two parts. First we examined the combined effects of $\mathrm{S}+\mathrm{P}$ and calcium emissions; then, we separately examined the combination of phosphorus and calcium emissions. These analyses are based on multiple regression models applied to two performance measures - predicted NRE and change in predicted NRE $(\triangle \mathrm{NRE})$ - as discussed in Section 2.2.5.

Table 9 summarizes the statistical correlations from the four sets of regression analyses (NRE vs. $\mathrm{S}+\mathrm{P}$ exposure, NRE vs. phosphorus exposure, $\triangle \mathrm{NRE}$ vs. $\mathrm{S}+\mathrm{P}$ exposure, $\Delta \mathrm{NRE}$ vs. phosphorus exposure) based on the 400-hour test results. Because the performance measures at 200, 300, and 400 are derived from the same model, only the correlations from the model results at 400 hours are presented in this table. For each performance measure (NRE or $\triangle N R E$ ), Table 9 lists the correlation coefficients (R-Squared) for three models fit to data from the composite emissions results.

The first two models are the simple linear regression models on $\mathrm{S}+\mathrm{P}$ (or phosphorus) and calcium exposures, respectively. For example, in the first row of the table we see that calcium exposure is not a significant predictor of performance while $\mathrm{S}+\mathrm{P}$ exposure is a significant predictor of performance at 400 hours. When calcium and $\mathrm{S}+\mathrm{P}$ are both included in the model, the estimated correlation increases to $69 \%$. The strongest statistically significant correlation between a performance measure and a single exposure level occurs between $\triangle \mathrm{NRE}$ and the total exposure to phosphorus. The correlation is $78 \%$. The level of calcium exposure improves the statistical correlation to $83 \%$, but the estimated improvement is not statistically significant. 
Table 9. Correlation Coefficients from Regressions of $\mathrm{NO}_{\mathrm{x}}$ Performance Measures (NRE and $\Delta$ NRE) on Exposures to S+P, Phosphorus, and Calcium

\begin{tabular}{|c|c|c|c|c|}
\hline \multirow{2}{*}{$\begin{array}{l}\text { Performance } \\
\text { Measure }\end{array}$} & $\mathbf{S}^{\text {Variable }}$ & $\mathbf{P}_{\text {Exposed }}$ & $\mathbf{C a}_{\text {Exposed }}$ & Both \\
\hline \multirow{2}{*}{\begin{tabular}{c} 
NRE at 400 Hours \\
\cline { 2 - 5 }
\end{tabular}} & $67 \%^{\mathrm{a}}$ & & $28 \%$ & $69 \%$ \\
\hline $\begin{array}{c}\text { Change in NRE } \\
\text { Over 400 Hours }\end{array}$ & $72 \%^{\mathrm{a}}$ & $69 \%^{\mathrm{a}}$ & $28 \%$ & $73 \%$ \\
\cline { 2 - 5 } & & $78 \%^{\mathrm{a}}$ & $33 \%$ & $76 \%$ \\
\hline
\end{tabular}

Significant effect $(p<0.05)$ for the composite mode

b. Significant effect $(p<0.05)$ but no improvement over best one variable model

Figure 7 demonstrates that increases in catalyst exposures to phosphorus and calcium at 200, 300 , and 400 hours of exposure are closely associated with a decline in NRE. There is a negative correlation between $\triangle \mathrm{NRE}$ and calcium exposure; however, as indicated in Table 9, the correlation is much stronger between $\triangle \mathrm{NRE}$ and phosphorus exposure.

The correlation coefficient does not directly determine the statistical significance of the relationship; however, for these analyses it generally follows that a correlation coefficient greater than $50 \%$ corresponds to a statistically significant $(\mathrm{p}<0.05)$ slope between $\mathrm{NRE}$ (or $\triangle \mathrm{NRE}$ ) and aging hours. The multiple regression model, which simultaneously accounts for both components, did not produce a significant improvement in model fit in any case. The appendix contains plots (Figure A-1) of NRE versus aging time. Table A-1 in the appendix contains the supporting regression results, including slope estimates for predicted NRE and change in predicted NRE versus exposure levels of $\mathrm{S}+\mathrm{P}$, phosphorus, and calcium. 

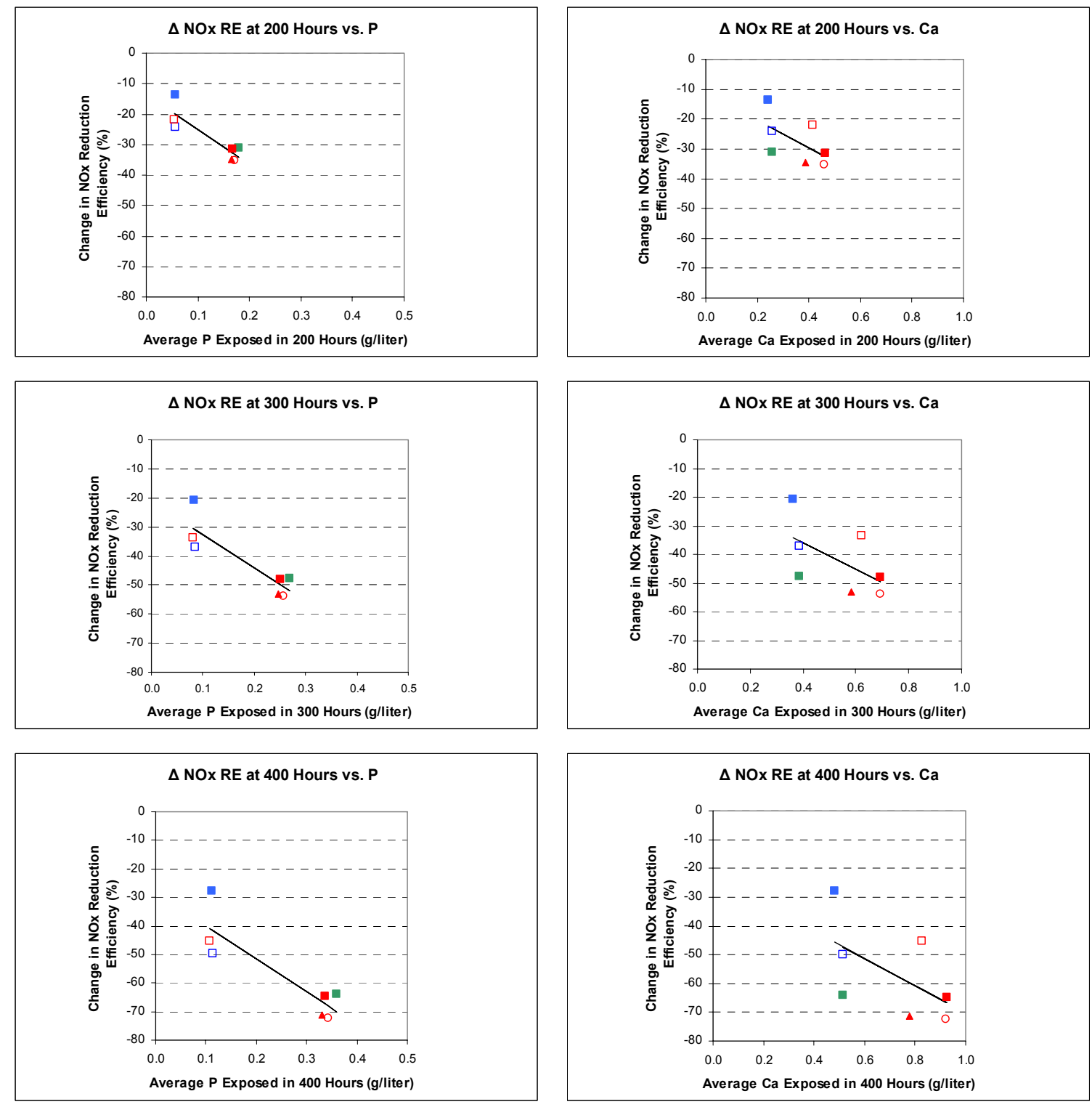

- Lo_Z/Lo_CaSulf-A1 aLo_Z/Lo_CaSulf-A7 Di_Z/Lo_CaSulf-B3 o Hi_Z/Hi_CaSal-E2

$\Delta \mathrm{Hi}$ ZZ/Hi_CaPhe-F4 $\square$ Lo_Z/Hi_CaSulf-C5 $\square$ Hi_Z/Hi_CaSulf-D6

Figure 7. Change in predicted NRE for composite mode vs. phosphorus and calcium exposure to catalysts through 200 to 400 hours of aging

\section{Impact of Other Oil Properties}

To investigate whether other oil properties provide a better fit to the performance measures, a stepwise multiple regression analysis was employed. This method attempts to find the bestfitting model when there are many combinations of candidate predictors. Given the small number of tests performed (seven - not including the test with doped fuel), it is not meaningful to have more than two or three predictors. 
For this analysis, elements found at trace levels $(<15 \mathrm{ppm})$ and properties that did not vary much among the test oils were excluded from the analysis. The properties of the test oils included in the analysis were the concentrations of sulfur, calcium, zinc, phosphorus, and nitrogen. We also used principal component analysis to help characterize the key features of the test oils, then applied stepwise regression analysis on the newly created variables. However this approach was not very helpful because it simply confirmed that levels of ZDDP (dominated by sulfur, phosphorus, and zinc) and calcium (determined by the level of detergent additive) were the key features of the test oils.

The stepwise regression analyses did not produce any new findings. As expected, the best predictors of catalyst performance were the levels of calcium and phosphorus.

\subsection{Effects of Sulfur and Phosphorus Deposits on Catalyst Performance}

This section focuses on the more direct relationship between the amount of deposits found on the catalyst and the catalyst's performance during aging. The following study question is addressed:

Q4.1 How does the catalyst performance vary as a function of the level of sulfur, phosphorus, and calcium deposits on the catalyst?

To evaluate the relationship between catalyst performance and the measured deposits of sulfur and phosphorus on the catalyst, we applied the same performance measures and analysis approach that was used to evaluate catalyst performance versus engine-out emissions (See Section 3.3).

Table 10 summarizes the results of this analysis. In general the results are similar to those obtained by modeling performance versus $\mathrm{S}+\mathrm{P}$, phosphorus, and calcium exposures in Section 3.3 (see Table 9), except that the relationship between the performance measures and the amount of $\mathrm{S}+\mathrm{P}$ deposited is not statistically significant at any time point. The correlations between the performance measures and the level of phosphorus deposits are statistically significant; but they are somewhat smaller than was observed for the models based on phosphorus emissions. This is likely due to the relative certainty of the exposure rate predictions relative to the measurement of the deposits. The largest correlation was between $\triangle \mathrm{NRE}$ and the level of P deposits on the catalyst. Figure 8 displays the plots of the change in NRE versus phosphorus and calcium deposit levels after 200, 300, and 400 hours of exposure. Table A-2 in the Appendix displays the supporting slope estimates for predicted NRE and change in predicted NRE versus deposit levels of $\mathrm{S}+\mathrm{P}$, phosphorus, and calcium. 
Table 10. Correlation Coefficients from Regressions of $\mathrm{NO}_{\mathrm{x}}$ Performance Measures (NRE and $\triangle$ NRE) on Deposit Levels of S+P, Phosphorus, and Calcium

\begin{tabular}{|c|c|c|c|c|}
\hline \multirow{2}{*}{$\begin{array}{l}\text { Performance } \\
\text { Measure }\end{array}$} & Variable & $\mathbf{P}_{\text {Deposited }}$ & Ca $_{\text {Deposited }}$ & Both \\
\hline \multirow{2}{*}{ NRE at 400 Hours } & $39 \%$ & & $37 \%$ & $52 \%$ \\
\cline { 2 - 5 } & & $60 \%{ }^{*}$ & $37 \%$ & $69 \%$ \\
\hline $\begin{array}{c}\text { Change in NRE } \\
\text { over400 Hours }\end{array}$ & $45 \%$ & & $30 \%$ & $52 \%$ \\
\cline { 2 - 5 } & & $65 \% *$ & $30 \%$ & $69 \%$ \\
\hline
\end{tabular}

* Significant effect $(\mathrm{p}<0.05)$ for the composite mode 

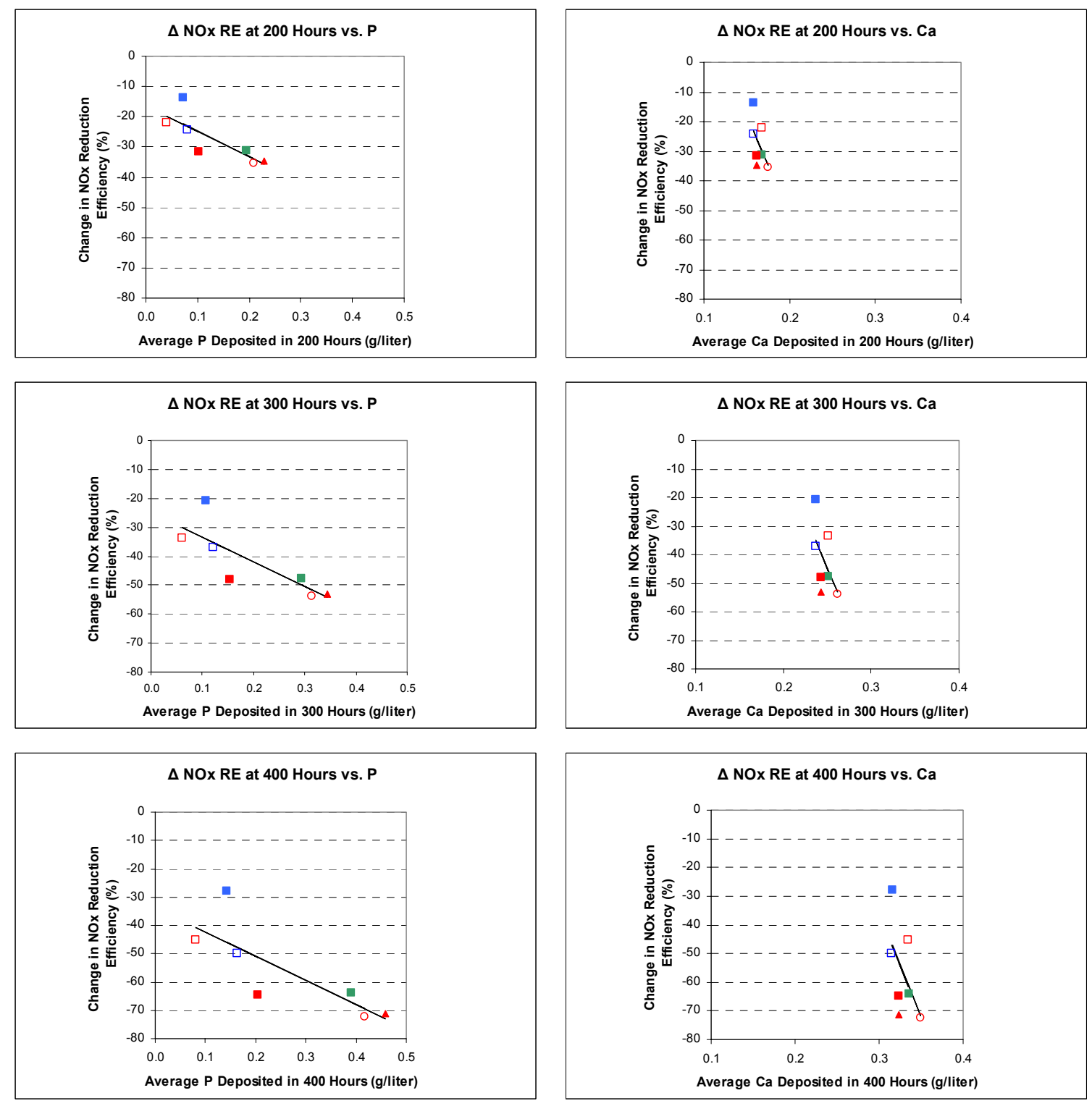

- Lo_Z/Lo_CaSulf-A1 aLo_Z/Lo_CaSulf-A7 Di_Z/Lo_CaSulf-B3 o Hi_Z/Hi_CaSal-E2 $\Delta \mathrm{Hi} Z / H i \_C a P h e-F 4 \quad \square$ Lo_Z/Hi_CaSulf-C5 $\square$ Hi_Z/Hi_CaSulf-D6

Figure 8. Change in predicted NRE for composite mode vs. phosphorus and calcium deposited on the aged catalysts through 200 to $\mathbf{4 0 0}$ hours of aging 


\subsection{Relative Effects of Lubricants and Fuels}

This section addresses the relative contributions of the lubricant and fuel to the deposition of sulfur on the catalyst and observed changes in NRE. The following study questions are addressed:

Q5.1 How do lubricant contributions to engine-out sulfur emissions and the sulfur deposits on the catalysts compare to those attributable to 15 -ppm sulfur fuel?

Q5.2 How does the degradation in NRE due to lubricant properties compare to the degradation that occurs with 15-ppm sulfur fuel?

Our analysis of the lubricant and fuel effects on exposure and deposits is based primarily on the estimated sulfur exposure and measured sulfur deposits for the three catalysts tested with Lubricant A. Tests 1 and 7 were performed with 0.6-ppm sulfur fuel, and test 8 was conducted with 15-ppm sulfur fuel. Results from the test with a high-sulfur lubricant (Oil D with $4197 \mathrm{ppm}$ sulfur) and $0.6 \mathrm{ppm}$ sulfur fuel are included for reference. Table 11 shows the calculation of sulfur recovery (percent of exposed sulfur that is deposited on the catalyst) based on the exposure of sulfur from the lubricant, fuel used on-board the engine, and fuel used as a reductant. Alternatively, Table 12 performs the same calculations with the reductant fuel excluded. Although there may be calibration biases affecting the measured sulfur deposits, the relative differences in recoveries between the tests run on low-sulfur fuel $(0.6 \mathrm{ppm})$. Those run on 15ppm sulfur fuel demonstrate that most, if not all, of the sulfur from the lubricant is captured by the catalyst, while the majority of the sulfur from the 15-ppm sulfur fuel that is sprayed on is passing through the catalyst $(100-37=63 \%$ of total sulfur emitted and $100-47=53 \%$ of the sulfur from the engine systems).

Table 11. Average Exposure and Deposition of Sulfur on the Catalyst during Aging Tests with Lubricant A and 0.6- and 15.0-ppm Sulfur Fuel; Engine and Dosing System Included

\begin{tabular}{|c|c|c|c|c|}
\hline $\begin{array}{c}\text { Lubricant ID - Test } \\
\text { Number }\end{array}$ & $\begin{array}{l}\text { Fuel } \\
\text { Sulfur }\end{array}$ & $\begin{array}{l}\text { Estimated Sulfur } \\
\text { Exposure (g/liter) }\end{array}$ & $\begin{array}{l}\text { Avg. Measured Sulfur } \\
\text { Deposited (g/liter) }\end{array}$ & $\begin{array}{l}\text { Percent } \\
\text { Recovery }\end{array}$ \\
\hline$A-1$ & \multirow{4}{*}{0.6} & 1.04 & 1.62 & $156 \%$ \\
\hline$A-7$ & & 1.00 & 1.24 & $125 \%$ \\
\hline Average & & 1.02 & 1.43 & $140 \%$ \\
\hline $\mathrm{D}$ & & 1.66 & 1.31 & $79 \%$ \\
\hline A-8 & 15 & 14.55 & 5.34 & $37 \%$ \\
\hline
\end{tabular}


Table 12. Average Exposure and Deposition of Sulfur on Catalyst during Aging Tests with Lubricant A and 0.6- and 15.0-ppm Sulfur Fuel; Engine Only

\begin{tabular}{|c|c||c|c|c|}
\hline $\begin{array}{c}\text { Lubricant ID - Test } \\
\text { Number }\end{array}$ & $\begin{array}{c}\text { Fuel } \\
\text { Sulfur }\end{array}$ & $\begin{array}{c}\text { Estimated Sulfur } \\
\text { Exposure (g/liter) }\end{array}$ & $\begin{array}{c}\text { Avg. Measured Sulfur } \\
\text { Deposited (g/liter) }\end{array}$ & $\begin{array}{c}\text { Percent } \\
\text { Recovery }\end{array}$ \\
\hline A-1 & \multirow{3}{*}{0.6} & 0.91 & 1.62 & $178 \%$ \\
\hline An-7 & 0.86 & 1.24 & $144 \%$ \\
\hline Average & & 0.89 & 1.43 & $161 \%$ \\
\hline D & 15 & 1.54 & 1.31 & $85 \%$ \\
\hline A-8 & 11.44 & 5.34 & $47 \%$ \\
\hline
\end{tabular}

Figure 9 compares the NRE achieved with the 0.6-ppm and 15-ppm sulfur fuel, and Lubricant A. With the 15-ppm sulfur fuel, the catalyst efficiency is reduced to less than $40 \%$ within the first 100 hours of operation, while the average efficiency with the low-sulfur fuel is still above $40 \%$ at 400 hours.

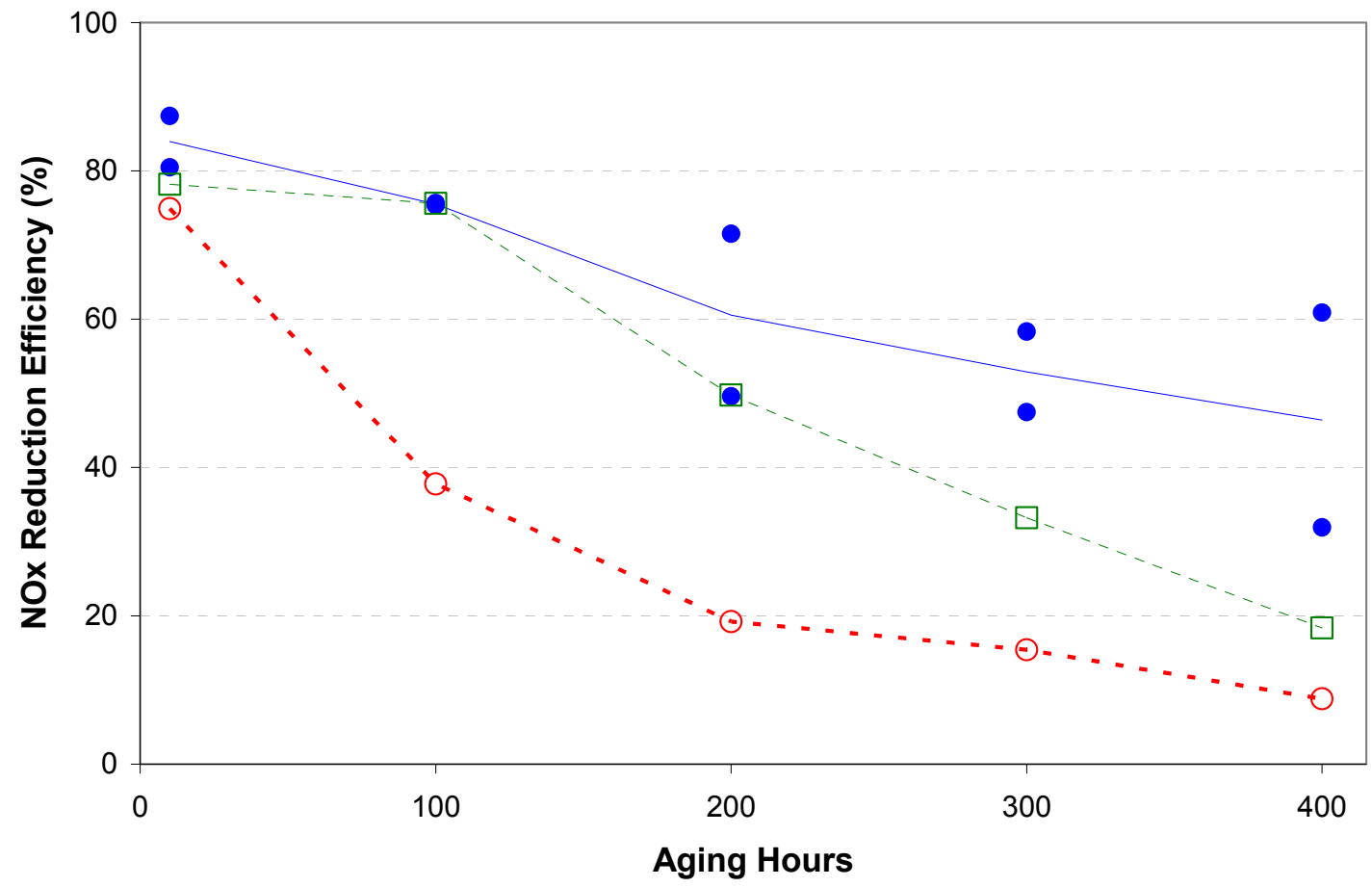

- Oil A with 0.6 ppm S Fuel = ๑ - Oil A with 15 ppm S Fuel - $\square--$ Oil D with 0.6 ppm S Fuel

Figure 9. Comparison of catalyst NRE when testing under three conditions: Oil A (1695 ppm sulfur) with 0.6-ppm sulfur fuel, Oil A with 15-ppm sulfur fuel, and Oil D (4197 ppm sulfur) with $0.6-p p m$ sulfur fuel 


\section{Section 4: Conclusions}

The following is a summary of the significant conclusions from the study.

\section{Lube-Derived Emissions versus Sulfur and Phosphorus Deposits on the Catalyst}

- The amount of phosphorus deposited on the catalyst is correlated with the concentration of phosphorus in the lubricant, regardless of the type of calcium detergent used.

- When oils with a calcium sulfonate detergent are used, the levels of both phosphorus and sulfur deposited on the catalyst are highly correlated with their concentration in the oil. However, the percentages of exposed phosphorus and sulfur that are deposited on the catalyst are significantly reduced (by $54 \%$ ) when the lubricant contains higher levels $(>3,100 \mathrm{ppm}$ versus $<2,200 \mathrm{ppm})$ of calcium sulfonate detergent (Figure 10).

- Approximately 50\% of the accumulated sulfur is deposited in the front third of the catalyst. The middle and rear of the catalyst receive approximately $30 \%$ and $20 \%$ of the sulfur, respectively. The corresponding percentages of phosphorus deposits are approximately $70 \%, 20 \%$, and 10\%, respectively (Figure 11 ).

Although these findings are statistically significant, additional research is needed to reach definitive conclusions concerning the role of calcium detergent in reducing the amounts of lubricant-derived sulfur and phosphorus deposited on catalysts. Also, system design, especially the order of emission control components in the exhaust system, will to a large extent dictate the system's sensitivity to lubricant-derived species. In this study, the NAC was the first and only device in the exhaust. Other systems may employ DPFs and/or DOCs in front of the NAC. With those designs, one might expect a majority of the lube components to be trapped by the device prior to reaching the $\mathrm{NO}_{\mathrm{x}}$ adsorber. Nonetheless, the effects observed in this study should be considered when next-generation engines and oils used in those engines are developed. 


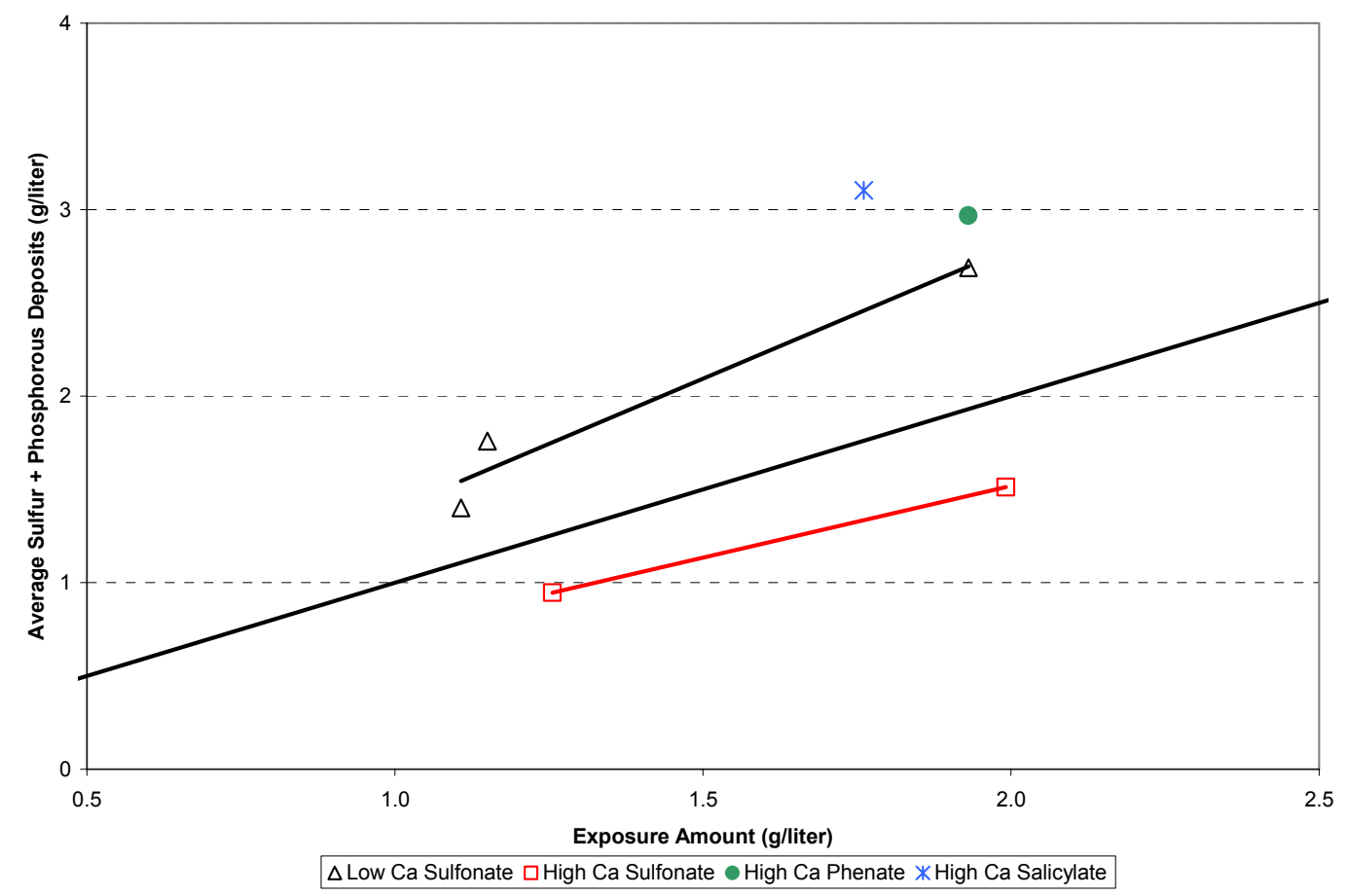

Figure 10. Levels of sulfur and phosphorus deposited on the catalyst as a function of the corresponding levels of lubricant-derived exposure and type of calcium detergent used in the lubricant

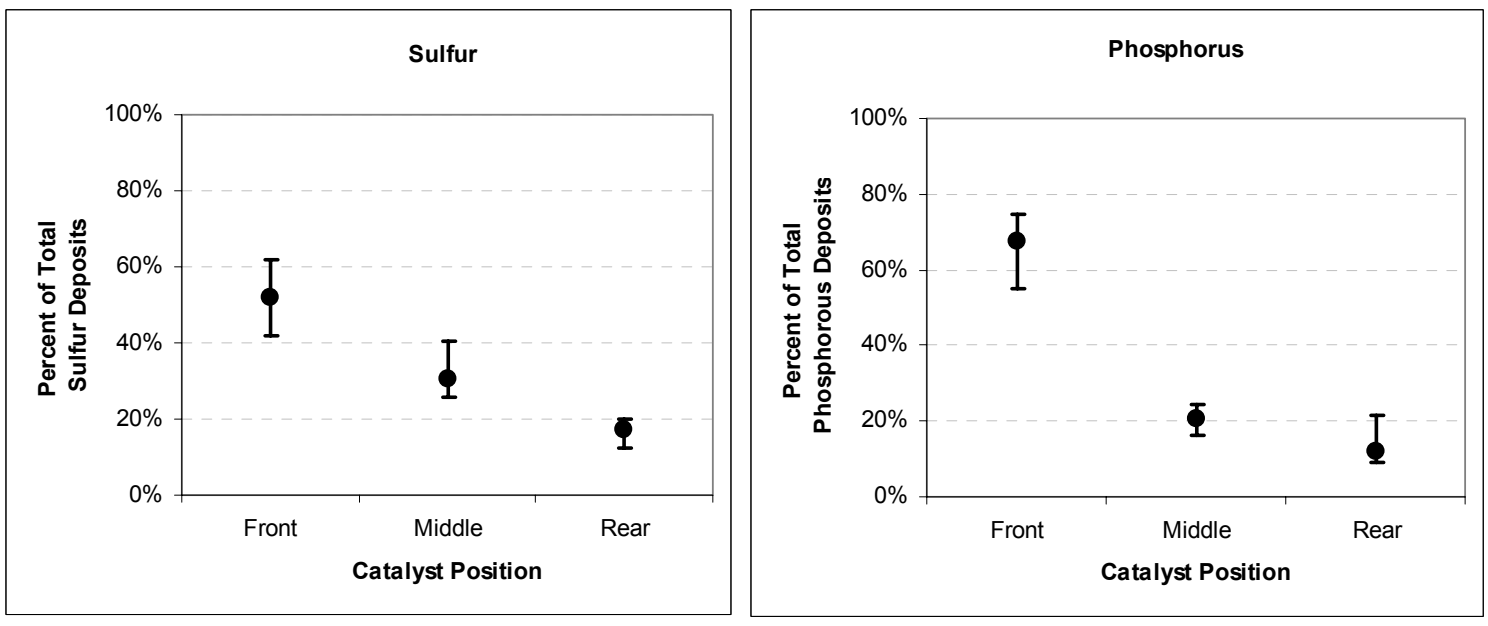

Figure 11. Percentage of total sulfur and phosphorus deposits distributed along the length of the catalyst (front toward engine, rear toward tailpipe) 


\section{Catalyst Performance versus Exposure to Lubricant-Derived Sulfur and Phosphorus}

The NRE of the catalyst was significantly affected $\left(\mathrm{R}^{2}=78 \%\right)$ by the level of phosphorus in the lubricant. As shown in Figure 12, NRE decreased by $70 \%$ after 400 hours of testing with high levels of lubricant-derived phosphorus exposure $(\sim 0.35 \mathrm{~g} / \mathrm{l})$. The decrease was $40 \%$ with phosphorus exposures of approximately $0.1 \mathrm{~g} / \mathrm{l}$. The initial NRE of the catalyst was between $75 \%$ and $90 \%$.

Because the levels of phosphorus and sulfur in the tested lubricants were correlated, it is not possible to determine which element had the greater effect on catalyst performance. Both elements were deposited on the catalyst, suggesting that lubricants containing higher concentrations of ZDDP adversely impact NAC performance. Further investigation would be required to characterize the nature of the deposits and the mechanism of the deactivation.

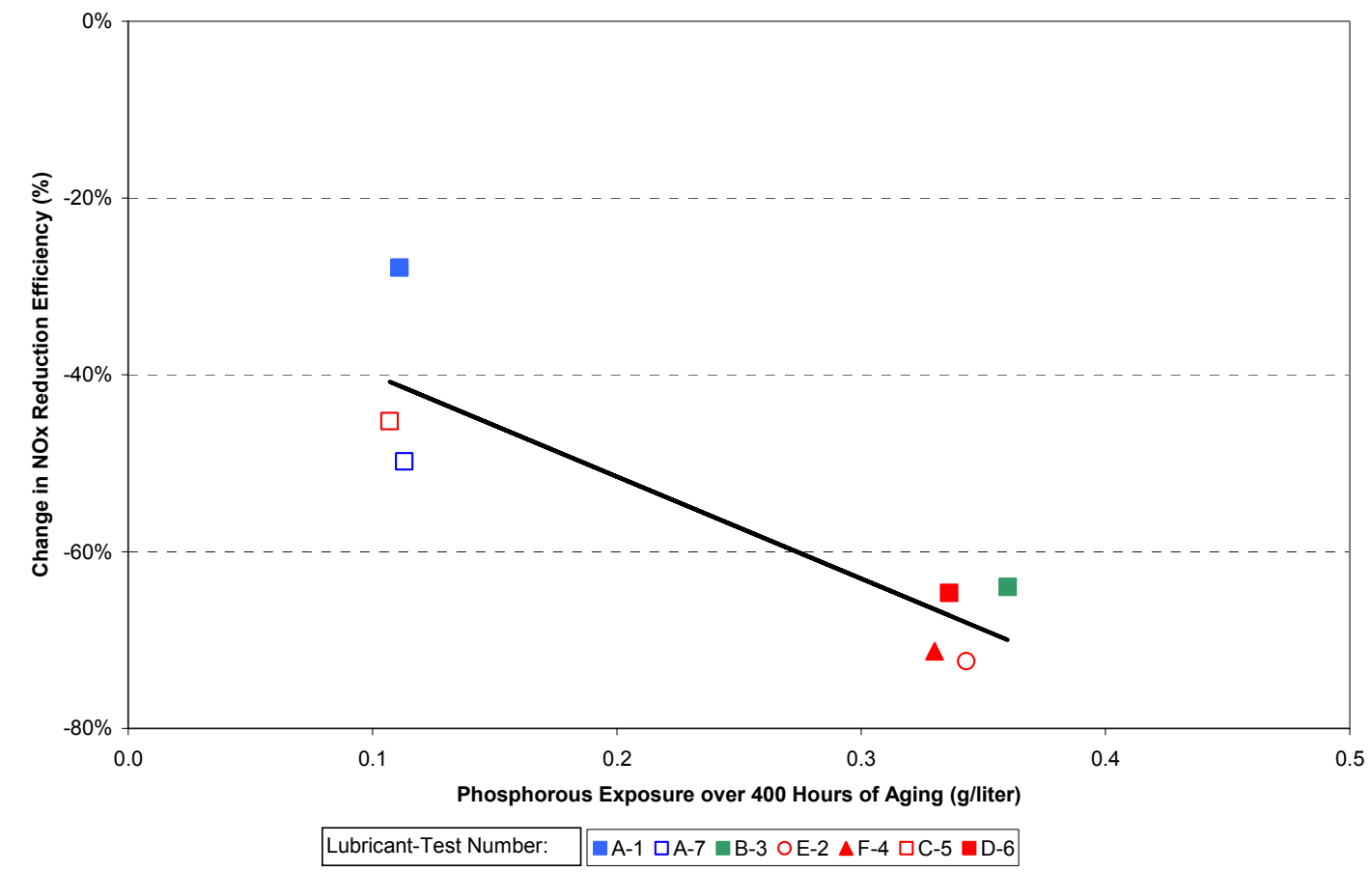

Figure 12. Change in NRE over 400 hours of testing as a function of the total exposure to lubricant-derived phosphorus emissions 


\section{Relative Contributions of Lubricant and Fuel Properties on Catalyst Performance}

NRE of the catalyst was reduced by $40 \%$ over 400 hours when the low-sulfur oil (Oil A with 1695 ppm sulfur) was tested with 0.6 ppm sulfur fuel; however, when the same oil was tested with 15 ppm sulfur fuel, there was a 40\% drop in NRE within the first 100 hours. Tests with high-sulfur oil (Oil D with $4197 \mathrm{ppm}$ sulfur) and the $0.6 \mathrm{ppm}$ sulfur fuel provided intermediate results (Figure 13).

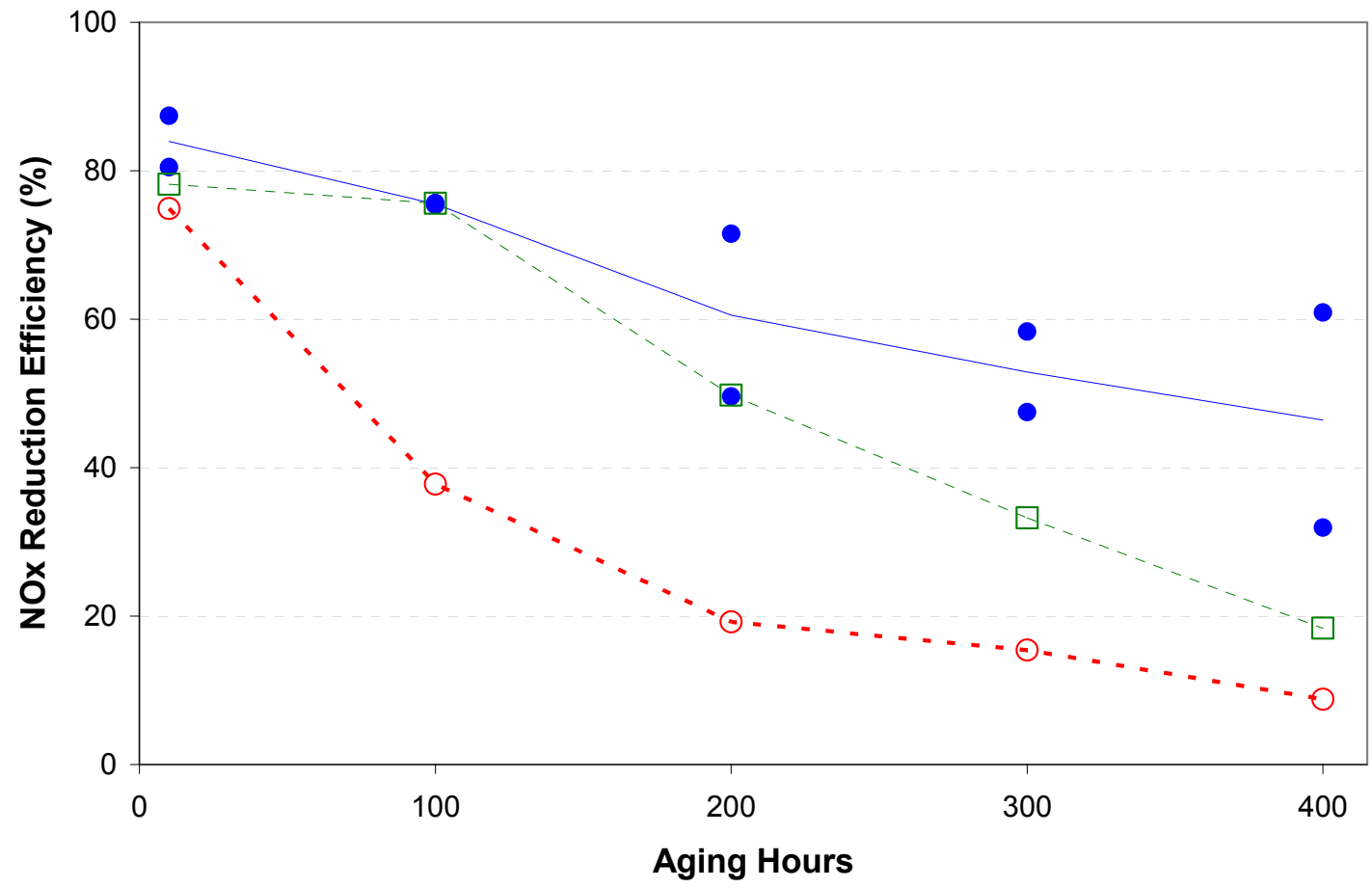

- Oil A with 0.6 ppm S Fuel - 0 - Oil A with 15 ppm S Fuel - $\square--$ Oil D with 0.6 ppm S Fuel

Figure 13. Comparison of catalyst NRE when testing under three conditions: Oil A (1695 ppm sulfur) with $0.6 \mathrm{ppm}$ sulfur fuel, Oil A with $15 \mathrm{ppm}$ sulfur fuel, and Oil D (4197 ppm sulfur) with $0.6 \mathrm{ppm}$ sulfur fuel 


\section{References}

1. Culley, S.A.; McDonald, T.F.; Ball, D.J.; Kirby, C.W.; Hawes, S.W. (1996) "The Impact of Passenger Car Motor Oil Phosphorus Levels on Automotive Emissions Control Systems," Society of Automotive Engineers. SAE 961898.

2. Hubbard, C.P.; Darr, S.T.; Choksi, R.A.; Johnson, M.D.; McCabe, R.W. (2000) "Effects of Oil-Derived Contaminants on Emissions from TWC-Equipped Vehicles," Society of Automotive Engineers. SAE 2000-01-1881.

3. Ueda, F.,;Sugiyama, S.; Arimura, K.; Hamaguchi, S.; Akiyama, K. (1994) "Engine Oil Additive Effects on Deactivation of Monolithic Three-Way Catalysts and Oxygen Sensors," Society of Automotive Engineers. SAE 940746.

4. Advanced Petroleum-Based Fuels-Diesel Emissions Control Project (APBF-DEC) Lubricants Project, Phase 1 Summary, U.S. Department of Energy. (July 2004) DOE/GO102004-1948. Golden, CO: National Renewable Energy Laboratory. Available in PDF at http://www.nrel.gov/vehiclesandfuels/apbf/pdfs/dec_lub_ph1_report.pdf and http://www.nrel.gov/docs/fy04osti/36357.pdf. 


\section{Appendix: Supporting Results from Regression Analyses Presented in Sections $\mathbf{3 . 3}$ and $\mathbf{3 . 4}$}

Tables A-1 and A-2 contain correlation coefficients $\left(\mathrm{r}^{2}\right)$ and slope parameter estimates from regression models relating $\mathrm{NO}_{\mathrm{x}}$ Reduction Efficiency (NRE) and change in NRE with exposures (A-1) and deposits (A-2) of sulfur, S+P, and calcium. Standard errors and significance levels ( $\mathrm{p}$ values) associated with the slope estimates are provided.

Figure A-1 displays NRE versus aging time for test modes 1 through 6 and the composite mode. 
Table A-1. Estimates of Slopes for NRE versus Exposure to Sulfur, $S+P$, and Calcium

\begin{tabular}{|c|c|c|c|c|c|c|c|c|c|}
\hline \multirow[b]{2}{*}{ Model } & \multirow[b]{2}{*}{ Measure } & \multirow[b]{2}{*}{$\begin{array}{l}\text { Test } \\
\text { Hour }\end{array}$} & \multirow[b]{2}{*}{ R-square } & \multicolumn{3}{|c|}{$\beta_{1}^{* *}$} & \multicolumn{3}{|c|}{$\beta_{2}^{* * *}$} \\
\hline & & & & Estimate & $\begin{array}{c}\text { Standard } \\
\text { Error }\end{array}$ & $p$-value & Estimate & $\begin{array}{l}\text { Standard } \\
\text { Error }\end{array}$ & $p$-value \\
\hline \multirow{6}{*}{4} & \multirow{3}{*}{ NRE } & 200 & $58 \%$ & -34.89 & 18.94 & 0.139 & -13.77 & 38.18 & 0.737 \\
\hline & & 300 & $66 \%$ & -33.64 & 15.69 & 0.099 & -15.04 & 31.62 & 0.659 \\
\hline & & 400 & $69 \%$ & -33.01 & 14.30 & 0.082 & -15.67 & 28.83 & 0.616 \\
\hline & \multirow{3}{*}{$\begin{array}{c}\text { Change in } \\
\text { NRE }\end{array}$} & 200 & $76 \%$ & -29.58 & 11.22 & 0.058 & -16.68 & 22.62 & 0.502 \\
\hline & & 300 & $76 \%$ & -30.10 & 11.42 & 0.058 & -16.97 & 23.02 & 0.502 \\
\hline & & 400 & $76 \%$ & -30.36 & 11.51 & 0.058 & -17.12 & 23.21 & 0.502 \\
\hline \multirow{6}{*}{5} & \multirow{3}{*}{ NRE } & 200 & $57 \%$ & -38.24 & 15.00 & 0.051 & & & \\
\hline & & 300 & $64 \%$ & -37.30 & 12.57 & 0.031 * & & & \\
\hline & & 400 & $67 \%$ & -36.83 & 11.55 & 0.024 * & & & \\
\hline & \multirow{3}{*}{$\begin{array}{c}\text { Change in } \\
\text { NRE }\end{array}$} & 200 & $72 \%$ & -33.64 & 9.32 & $0.015^{*}$ & & & \\
\hline & & 300 & $72 \%$ & -34.23 & 9.48 & $0.015^{*}$ & & & \\
\hline & & 400 & $72 \%$ & -34.53 & 9.56 & $0.015^{*}$ & & & \\
\hline \multirow{6}{*}{6} & \multirow{3}{*}{ NRE } & 200 & $22 \%$ & & & & -48.28 & 40.46 & 0.286 \\
\hline & & 300 & $26 \%$ & & & & -48.31 & 36.14 & 0.239 \\
\hline & & 400 & $28 \%$ & & & & -48.32 & 34.32 & 0.218 \\
\hline & \multirow{3}{*}{$\begin{array}{c}\text { Change in } \\
\text { NRE }\end{array}$} & 200 & $33 \%$ & & & & -45.94 & 29.17 & 0.176 \\
\hline & & 300 & $33 \%$ & & & & -46.75 & 29.68 & 0.176 \\
\hline & & 400 & $33 \%$ & & & & -47.15 & 29.94 & 0.176 \\
\hline \multirow{6}{*}{7} & \multirow{3}{*}{ NRE } & 200 & $58 \%$ & -109.27 & 58.42 & 0.135 & -18.90 & 36.58 & 0.633 \\
\hline & & 300 & $68 \%$ & -107.65 & 46.98 & 0.084 & -19.36 & 29.42 & 0.546 \\
\hline & & 400 & $73 \%$ & -106.83 & 41.83 & 0.063 & -19.59 & 26.20 & 0.496 \\
\hline & \multirow{3}{*}{$\begin{array}{l}\text { Change in } \\
\text { NRE }\end{array}$} & 200 & $83 \%$ & -99.17 & 29.44 & 0.028 * & -19.27 & 18.44 & 0.355 \\
\hline & & 300 & $83 \%$ & -100.91 & 29.96 & 0.028 * & -19.61 & 18.76 & 0.355 \\
\hline & & 400 & $83 \%$ & -101.78 & 30.22 & 0.028 * & -19.78 & 18.92 & 0.355 \\
\hline \multirow{6}{*}{8} & \multirow{3}{*}{ NRE } & 200 & $56 \%$ & -122.24 & 48.74 & 0.054 & & & \\
\hline & & 300 & $65 \%$ & -120.92 & 39.95 & 0.029 * & & & \\
\hline & & 400 & $69 \%$ & -120.27 & 36.08 & $0.021^{*}$ & & & \\
\hline & \multirow{3}{*}{$\begin{array}{c}\text { Change in } \\
\text { NRE }\end{array}$} & 200 & $78 \%$ & -112.39 & 26.84 & 0.009 * & & & \\
\hline & & 300 & $78 \%$ & -114.36 & 27.31 & 0.009 * & & & \\
\hline & & 400 & $78 \%$ & -115.35 & 27.54 & 0.009 * & & & \\
\hline \multirow{6}{*}{9} & \multirow{3}{*}{ NRE } & 200 & $22 \%$ & & & & -48.28 & 40.46 & 0.286 \\
\hline & & 300 & $26 \%$ & & & & -48.31 & 36.14 & 0.239 \\
\hline & & 400 & $28 \%$ & & & & -48.32 & 34.32 & 0.218 \\
\hline & \multirow{3}{*}{$\begin{array}{c}\text { Change in } \\
\text { NRE }\end{array}$} & 200 & $33 \%$ & & & & -45.94 & 29.17 & 0.176 \\
\hline & & 300 & $33 \%$ & & & & -46.75 & 29.68 & 0.176 \\
\hline & & 400 & $33 \%$ & & & & -47.15 & 29.94 & 0.176 \\
\hline
\end{tabular}

* Significant effect $(p<0.05)$

${ }^{* *} \beta_{1}=$ Slope with respect to $S+P_{\text {Exposed }}$ for models 4,5 , and $6 ; \beta_{1}=$ Slope with respect to $P_{\text {Exposed }}$ for models 7,8 , and 9

${ }^{* * *} \beta_{2}=$ Slope with respect to Ca $a_{\text {Exposed }}$ for Models $4-9$. 
Table A-2. Estimates of Slopes for NRE versus Deposit Levels of Sulfur, S+P, and Calcium

\begin{tabular}{|c|c|c|c|c|c|c|c|c|c|}
\hline \multirow[b]{2}{*}{ Model } & \multirow[b]{2}{*}{ Measure } & \multirow[b]{2}{*}{ Test Hour } & \multirow[b]{2}{*}{ R-square } & \multicolumn{3}{|c|}{$\beta_{1}^{* *}$} & \multicolumn{3}{|c|}{$\beta_{2}^{* * *}$} \\
\hline & & & & Estimate & $\begin{array}{c}\text { Standard } \\
\text { Error }\end{array}$ & $p$-value & Estimate & $\begin{array}{c}\text { Standard } \\
\text { Error }\end{array}$ & $p$-value \\
\hline \multirow{6}{*}{10} & \multirow{3}{*}{ NRE } & 200 & $49 \%$ & -7.87 & 9.65 & 0.460 & -801.97 & 676.33 & 0.301 \\
\hline & & 300 & $51 \%$ & -8.71 & 8.64 & 0.370 & -671.28 & 605.64 & 0.330 \\
\hline & & 400 & $52 \%$ & -9.13 & 8.24 & 0.330 & -605.94 & 578.00 & 0.354 \\
\hline & \multirow{3}{*}{$\begin{array}{c}\text { Change in } \\
\text { NRE }\end{array}$} & 200 & $52 \%$ & -9.87 & 7.25 & 0.245 & -389.42 & 508.36 & 0.486 \\
\hline & & 300 & $52 \%$ & -10.04 & 7.38 & 0.245 & -396.25 & 517.28 & 0.486 \\
\hline & & 400 & $52 \%$ & -10.13 & 7.44 & 0.245 & -399.67 & 521.74 & 0.486 \\
\hline \multirow{6}{*}{11} & \multirow{3}{*}{ NRE } & 200 & $31 \%$ & -13.17 & 8.89 & 0.199 & & & \\
\hline & & 300 & $36 \%$ & -13.15 & 7.83 & 0.154 & & & \\
\hline & & 400 & $39 \%$ & -13.13 & 7.38 & 0.135 & & & \\
\hline & \multirow{3}{*}{$\begin{array}{c}\text { Change in } \\
\text { NRE }\end{array}$} & 200 & $45 \%$ & -12.44 & 6.16 & 0.099 & & & \\
\hline & & 300 & $45 \%$ & -12.66 & 6.26 & 0.099 & & & \\
\hline & & 400 & $45 \%$ & -12.77 & 6.32 & 0.099 & & & \\
\hline \multirow{6}{*}{12} & \multirow{3}{*}{ NRE } & 200 & $40 \%$ & & & & -1057.57 & 579.08 & 0.127 \\
\hline & & 300 & $39 \%$ & & & & -954.09 & 537.69 & 0.136 \\
\hline & & 400 & $37 \%$ & & & & -902.35 & 523.75 & 0.146 \\
\hline & \multirow{3}{*}{$\begin{array}{l}\text { Change in } \\
\text { NRE }\end{array}$} & 200 & $30 \%$ & & & & -709.77 & 487.43 & 0.205 \\
\hline & & 300 & $30 \%$ & & & & -722.23 & 495.99 & 0.205 \\
\hline & & 400 & $30 \%$ & & & & -728.45 & 500.26 & 0.205 \\
\hline \multirow{6}{*}{13} & \multirow{3}{*}{ NRE } & 200 & $63 \%$ & -71.34 & 45.58 & 0.193 & -656.46 & 570.64 & 0.314 \\
\hline & & 300 & $67 \%$ & -73.17 & 39.37 & 0.137 & -542.75 & 492.90 & 0.333 \\
\hline & & 400 & $69 \%$ & -74.08 & 37.00 & 0.116 & -485.89 & 463.19 & 0.353 \\
\hline & \multirow{3}{*}{$\begin{array}{c}\text { Change in } \\
\text { NRE }\end{array}$} & 200 & $69 \%$ & -72.97 & 32.29 & 0.087 & -299.55 & 404.26 & 0.500 \\
\hline & & 300 & $69 \%$ & -74.25 & 32.86 & 0.087 & -304.80 & 411.36 & 0.500 \\
\hline & & 400 & $69 \%$ & -74.89 & 33.14 & 0.087 & -307.43 & 414.90 & 0.500 \\
\hline \multirow{6}{*}{14} & \multirow{3}{*}{ NRE } & 200 & $50 \%$ & -94.89 & 42.02 & 0.074 & & & \\
\hline & & 300 & $57 \%$ & -92.64 & 35.92 & 0.05 * & & & \\
\hline & & 400 & $60 \%$ & -91.51 & 33.39 & 0.041 * & & & \\
\hline & \multirow{3}{*}{$\begin{array}{c}\text { Change in } \\
\text { NRE }\end{array}$} & 200 & $65 \%$ & -83.71 & 27.52 & 0.029 * & & & \\
\hline & & 300 & $65 \%$ & -85.18 & 28.00 & 0.029 * & & & \\
\hline & & 400 & $65 \%$ & -85.92 & 28.25 & 0.029 * & & & \\
\hline \multirow{6}{*}{15} & \multirow{3}{*}{ NRE } & 200 & $40 \%$ & & & & -1057.57 & 579.08 & 0.127 \\
\hline & & 300 & $39 \%$ & & & & -954.09 & 537.69 & 0.136 \\
\hline & & 400 & $37 \%$ & & & & -902.35 & 523.75 & 0.146 \\
\hline & \multirow{3}{*}{$\begin{array}{c}\text { Change in } \\
\text { NRE }\end{array}$} & 200 & $30 \%$ & & & & -709.77 & 487.43 & 0.205 \\
\hline & & 300 & $30 \%$ & & & & -722.23 & 495.99 & 0.205 \\
\hline & & 400 & $30 \%$ & & & & -728.45 & 500.26 & 0.205 \\
\hline
\end{tabular}

* Significant effect $(p<0.05)$

${ }^{* *} \beta_{1}=$ Slope with respect to $S+P_{\text {Deposited }}$ for Models 10,11 , and $12 ; \beta_{1}=$ Slope with respect to $P_{\text {Deposited }}$ for Models 13, 14, and 15

${ }^{* * *} \beta_{2}=$ Slope with respect to $\mathrm{Ca}_{\text {Deposited }}$ for Models $10-15$. 

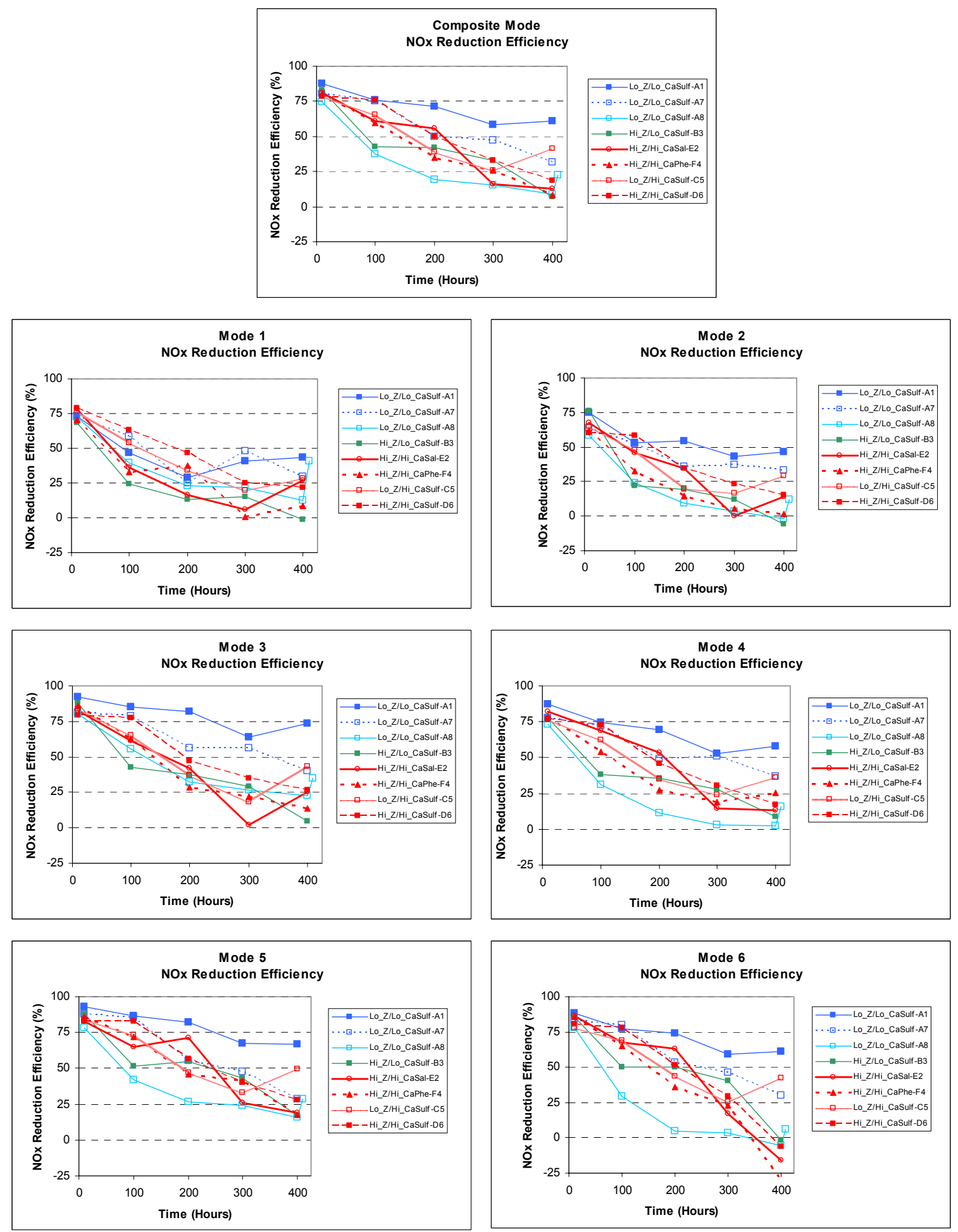

Figure A-1. NRE versus aging time for composite mode and modes 1 to 6 


\section{A Strong Energy Portfolio for a Strong America}

Energy efficiency and clean, renewable energy will mean a stronger economy, a cleaner environment, and greater energy independence for America. Working with a wide array of state, community, industry, and university partners, the U.S. Department of Energy's Office of Energy Efficiency and Renewable Energy invests in a diverse portfolio of energy technologies.

\section{Produced for the U.S. Department of Energy by the} National Renewable Energy Laboratory

For more information contact:

\section{EERE Information Center}

1-877-EERE-INF (1-877-337-3463)

DOE/GO-102006-2318

May 2006 